\title{
Effect of Bi203-B203 as a Sintering aid in Microstructure and Dielectric Properties of Fe2Mo3012 Electroceramic.
}

Eduardo Araújo

Universidade Federal do Ceara

Marcelo Silva

Universidade Federal do Ceara

Mauricio Pereira

Universidade Federal do Ceara

Antonio Sombra

Universidade Federal do Ceara

Igor Vasconcelos

Universidade Federal do Ceara

Pierre Fechine ( $\nabla$ fechine@ufc.br)

https://orcid.org/0000-0002-7822-2354

\section{Research Article}

Keywords: LTCC, Fe2Mo3012, Microwave, Impedance Spectroscopy

Posted Date: July 21st, 2020

DOl: https://doi.org/10.21203/rs.3.rs-45431/v1

License: (9) (i) This work is licensed under a Creative Commons Attribution 4.0 International License.

Read Full License 


\title{
Effect of $\mathrm{Bi}_{2} \mathrm{O}_{3}-\mathrm{B}_{2} \mathrm{O}_{3}$ as a sintering aid in microstructure and dielectric properties of $\mathrm{Fe}_{2} \mathrm{Mo}_{3} \mathrm{O}_{12}$ electroceramic.
}

\author{
E. V. Araújo ${ }^{a}$, M. A. S. Silva ${ }^{b}$, M. S. Pereira ${ }^{c}$, A. S. B. Sombra ${ }^{b}$, I. F. Vasconcelos ${ }^{\text {c }}$, P. B. A. \\ Fechine $^{\mathrm{a}, *}$.
}

a: Grupo de Química de Materiais Avançados (GQMat), Departamento de Química Analítica e Físico-Química, Universidade Federal do Ceará - UFC, Campus do Pici, CP 12100, CEP 60451-970, Fortaleza, CE, Brazil.

b: Laboratório de Telecomunicações e Ciência e Engenharia de Materiais (LOCEM), Departamento de Física, Universidade Federal do Ceará, Brazil.

c: Laboratório de Materiais Avançados, Departamento de Engenharia Metalúrgica e de Materiais, Universidade Federal do Ceará, Brazil.

\section{Authors e-mails:}

E. V. Araújo eduardo.qufc@hotmail.com

M. A. S. Silva marceloassilva@yahoo.com.br

M. S. Pereiramauriciosousa@alu.ufc.br
A. S. B. Sombra asbsombra@gmail.com
I. F. Vasconcelos ifvasco@ufc.br

*Corresponding Author:

E-mail address: fechine@ufc.br (P. B. A. Fechine)

Phone: +55(85)33669047 


\begin{abstract}
Molybdates from $\mathrm{A}_{2} \mathrm{Mo}_{3} \mathrm{O}_{12}$ family have been widely investigated due to its low sintering temperature, low thermal expansion coefficient, and low dielectric loss. $\mathrm{Fe}_{2} \mathrm{Mo}_{3} \mathrm{O}_{12}$ (FMO) is an oxide from this family and widely used in the catalytic field. The aim of this work is to evaluate the influence of the $\mathrm{Bi}_{2} \mathrm{O}_{3}-\mathrm{B}_{2} \mathrm{O}_{3}$ as a sintering aid in the microstructure and dielectric properties of FMO. The diffraction results showed that the FMO with the monoclinic structure phase was obtained after the calcination process $\left(650^{\circ} \mathrm{C}\right)$. Mössbauer spectroscopy showed the formation of $\mathrm{Fe}_{2} \mathrm{O}_{3}$ after the sintering process at $800{ }^{\circ} \mathrm{C}$. The scanning electronmicroscopic demonstrates an increase of the grain as a function of sintering aid concentration. The samples were analyzed by using the impedance spectroscopy at radiofrequency with temperature variation. The Nyquist diagram obtained in this temperature range was fitted from an equivalent circuit with three R-CPE associations, corresponding to the morphology of the electroceramics. For dielectric properties in the microwave, all the samples showed values of $\varepsilon_{r}$ lower than 10 . Values of $Q x f$ above $14132.35 \mathrm{GHz}$ were achieved. The thermal stability was evaluated by the temperature coefficient of resonant frequency $\left(\tau_{f}\right)$. The lowest $\tau_{f}$ values of $-6.55 \mathrm{ppm} /{ }^{\circ} \mathrm{C}$ and $-4.35 \mathrm{ppm} /{ }^{\circ} \mathrm{C}$ (near-zero) were measured to FMO and FMO mixed with $7.5 \mathrm{wt} \% \mathrm{Bi}_{2} \mathrm{O}_{3}-\mathrm{B}_{2} \mathrm{O}_{3}$, respectively. Based on these results, FMO can be used to low permittivity ceramic for low temperature co-fired ceramics (LTCC) applications, antenna substrate, and millimeter-wave range.
\end{abstract}

Keywords: LTCC; $\mathrm{Fe}_{2} \mathrm{Mo}_{3} \mathrm{O}_{12}$; Microwave; Impedance Spectroscopy. 


\section{Introduction.}

The electroceramics emerged as an excellent option for integration and miniaturization of electronic circuits, making smaller and more efficient systems [1]. Due to the advances in telecommunications, it is required that the materials have appropriated dielectric constant $\left(\varepsilon_{r}\right)$, low dielectric loss $(\tan \delta)$, near-zero temperature coefficient of resonant frequency $\left(\tau_{f}\right)$, highquality factor $(Q x f)$, temperature stable and versatile [2,3]. Electroceramics are widely used in the manufacturing of microwave electronic devices, dielectric substrates, resonators owing to their easy integration in chips [4]. Most of these ceramics require high sintering temperature, which can be a factor that hinders the integration of them into an electronic circuit [5]. Therefore, low temperature co-fired ceramics (LTCC) were developed by adding low quantities of melting temperature oxides, such as $\mathrm{Bi}_{2} \mathrm{O}_{3}$ [6,7], $\mathrm{B}_{2} \mathrm{O}_{3}$ [8], $\mathrm{TeO}_{2}$ [9-11], $\mathrm{V}_{2} \mathrm{O}_{5}$ [11], among others [12-14], which allows the sintering process below $950{ }^{\circ} \mathrm{C}$.

Recent studies point $\mathrm{MoO}_{3}$ based electroceramic as an excellent option for LTCC application [15-20], with high $Q x f$ and low tan $\delta$. Nina Joseph and coworkers obtained $\mathrm{CuMoO}_{4}$ sintered at low temperature and completely compatible with the Al electrode and with $Q x f$ of $53000 \mathrm{GHz}$ and $\varepsilon_{r}$ of 7.9 [21]. Li-xia Pang et al obtained $\left(\mathrm{K}_{0.5} \mathrm{La}_{0.5}\right) \mathrm{MoO}_{4}$ with middle $\varepsilon_{r}, Q x f$ of $59000 \mathrm{GHz}$, and 0.0002 of tan $\delta$ [22]. However, LTCC molybdate based materials have high $\tau_{f}$ values $[2,5,21,23]$ and the addition of other compounds are necessary to shift the $\tau_{f}$ to near-zero values. Nina Joseph and coworkers added $\mathrm{Ag}_{2} \mathrm{O}$ in $\mathrm{CuMoO}_{4}\left(\tau_{f}=-36 \mathrm{ppm} .{ }^{\circ} \mathrm{C}^{-1}\right)$ to achieve composite with near-zero $\tau_{f}[24]$.

Molybdates belonging to $\mathrm{A}_{2} \mathrm{M}_{3} \mathrm{O}_{12}$ family, where $\mathrm{A}$ is a trivalent cation $\left(\mathrm{Fe}^{3+}, \mathrm{Al}^{3+}, \mathrm{Y}^{3+}\right.$, and other rare earths) and $\mathrm{M}$ is a hexavalent cation $\left(\mathrm{Mo}^{6+}\right.$ or $\left.\mathrm{W}^{6+}\right)$. They have been widely investigated due to their negative or near-zero thermal expansion coefficient $(\alpha)$ : $\mathrm{Y}_{2} \mathrm{Mo}_{3} \mathrm{O}_{12}$ [25], $\mathrm{Al}_{2} \mathrm{Mo}_{3} \mathrm{O}_{12}, \mathrm{Sc}_{2} \mathrm{Mo}_{3} \mathrm{O}_{12}$ [26], $\mathrm{Fe}_{2} \mathrm{Mo}_{3} \mathrm{O}_{12}$ [27], $\mathrm{In}_{2} \mathrm{~W}_{3} \mathrm{O}_{12}, \mathrm{Al}_{2} \mathrm{~W}_{3} \mathrm{O}_{12}, \mathrm{Sc}_{2} \mathrm{~W}_{3} \mathrm{O}_{12}$ [28], among others. The iron (III) molybdate $\left(\mathrm{Fe}_{2} \mathrm{Mo}_{3} \mathrm{O}_{12}\right)$ has a monoclinic structure at room temperature and shows a monoclinic-to-orthorhombic transition between 510 and $520{ }^{\circ} \mathrm{C}[29$, 30]. Li, Z.W, and coworkers [29] had investigated the $\mathrm{Fe}_{2} \mathrm{Mo}_{3} \mathrm{O}_{12}$ (FMO) and they observed the low $\alpha$ of this phase. This property is desirable in the development of electronic devices, where it is needed a material which its dimensions do not change with the temperature changing [31].

FMO has been using to degradation reactions, for rhodamine-B using photocatalyst process, for example [32]. However, the application of FMO, as a potential LTCC, has never been 
made so far to our knowledge. In this sense, a $\mathrm{Bi}_{2} \mathrm{O}_{3}-\mathrm{B}_{2} \mathrm{O}_{3}$ mix is used as a sintering aid, the liquid phase of $\mathrm{Bi}_{2} \mathrm{O}_{3}$ allows the grain growth during the sintering process $[33,34]$, while $\mathrm{B}_{2} \mathrm{O}_{3}$ is usually employed as flux former [35]. Therefore, the purpose of this study was to evaluate the effect of $\mathrm{Bi}_{2} \mathrm{O}_{3}-\mathrm{B}_{2} \mathrm{O}_{3}$ mix in the microstructure, structure phase, and dielectric properties at radiofrequency and microwave range of FMO electroceramics.

\section{Methodology.}

FMO electroceramic was synthesized by solid-sate route using $\mathrm{Fe}_{2} \mathrm{O}_{3}$ (99\%, Sigma Aldrich) and $\mathrm{MoO}_{3}(99.5 \%$, Sigma Aldrich). These starting materials were ground and mixed in agate mortar following the stoichiometry, as described in equation 1.

$$
\mathrm{Fe}_{2} \mathrm{O}_{3(\mathrm{~s})}+3 \mathrm{MoO}_{3(\mathrm{~s})} \rightarrow \mathrm{Fe}_{2} \mathrm{Mo}_{3} \mathrm{O}_{12(\mathrm{~s})}
$$

The mixture was pressed into pellets and calcinated at $650{ }^{\circ} \mathrm{C}$ for $16 \mathrm{~h}$. The $\mathrm{Bi}_{2} \mathrm{O}_{3}-\mathrm{B}_{2} \mathrm{O}_{3}$ sintering aid was prepared using $\mathrm{Bi}_{2} \mathrm{O}_{3}\left(99.9 \%\right.$, Sigma Aldrich) and $\mathrm{B}_{2} \mathrm{O}_{3}$ (98\%, Sigma Aldrich) and was added in molar ratio 1:1 and mixed in Fritsch Pulverisette 6 planetary mill for $10 \mathrm{~h}$ with $370 \mathrm{rpm}$ as rotation speed. Milling was performed in sealed stainless-steel vials under air with stainless-steel balls. A ball mass ratio of $1: 9\left(\mathrm{Bi}_{2} \mathrm{O}_{3}-\mathrm{B}_{2} \mathrm{O}_{3}\right.$ powder mass : ball mass) was used.

For dielectric characterization, the samples were ground and mixed with polyvinyl alcohol (PVA) $10 \% \mathrm{v} / \mathrm{v}$ solution. $\mathrm{Bi}_{2} \mathrm{O}_{3}-\mathrm{B}_{2} \mathrm{O}_{3}$ was added as sintering aid and the samples were labeled as FMO-X $\left(\mathrm{X}=2.5,5.0\right.$ and $\left.7.5 \mathrm{wt} \% \mathrm{Bi}_{2} \mathrm{O}_{3}-\mathrm{B}_{2} \mathrm{O}_{3}\right)$. Then, each composition was pressed into cylindrical pellets and sintered at $800{ }^{\circ} \mathrm{C}$ for $6 \mathrm{~h}$. The volume of these pellets was determined by Archimedes' method to calculate their density. These pellets were polished on both faces and a silver paste (Joint Metal-PC200) was applied on them to ensure the electrical contact.

X-ray powder diffraction (XRPD) patterns were obtained by using a PANalytical diffractometer (Xpert Pro MPD) operating at $40 \mathrm{kV}$ and $40 \mathrm{~mA}$ in the Bragg-Brentano geometry, with a Co tube ( $\left.\mathrm{Ka}_{1}: 1.7889 \AA\right)$. The diffraction patterns were collected at room temperature from pulverized FMO calcinated and sintered samples. The diffractograms were obtained from $10^{\circ}$ to $60^{\circ}$ at a step size of $0.013^{\circ}$, with an analysis time of $70 \mathrm{~s}$ at each step, in a graphite monochromator in the plane geometry for diffracted beam. 
Mössbauer spectra were obtained using transmission mode at room temperature. The ${ }^{57} \mathrm{Co}$ radioactive source in Rh matrix was used mounted in speed controller scanning from $-10 \mathrm{~mm} \cdot \mathrm{s}^{-1}$ to $+10 \mathrm{~mm} \cdot \mathrm{s}^{-1}$ [36]. Spectra were also obtained for FMO calcinated and sintered samples.

Raman spectra were obtained using LabRAM Jobin-Yvon HORIBA spectometer, equipped with liquid nitrogen cooled CCD. A Laser beam was focused in the sample surface using OLYMPUS microscope lens and numeric opening of 0.75 , forming a spot of $4 \mu \mathrm{m}^{2}$ under the sample surface. The slits were adjusted to obtain a resolution of $2 \mathrm{~cm}^{-1}$

The surface's microstructure of the FMO based electroceramics was studied by scanning electron microscopy (SEM). Micrograph images were collected at room temperature using a FEG Quanta 450 with Energy-dispersive X-ray spectroscopy (EDS) in the SEM chamber, with an incident electron beam of $20 \mathrm{kV}$.

For dielectric measurements at the RF range, the samples were evaluated using a Solartron 1260 computer-controlled impedance analyzer as a function of frequency $(1 \mathrm{~Hz}-10 \mathrm{MHz})$ at different temperatures $\left(220^{\circ} \mathrm{C}-260^{\circ} \mathrm{C}\right)$. On the other hand, the dielectric measurements for the microwave range were evaluated with an Agilent Model PNA N5230A using the HakkiColeman method [37]. The Agilent PNA N5230A was also used to measure the $\tau_{f}$ of the FMO as described by Silva and his coworkers [38].

\section{Results and Discussion.}

In order to confirm the complete calcination of FMO and achieve the crystalline phase, all the samples were analyzed by XRPD technique and compared to $\mathrm{Fe}_{2} \mathrm{Mo}_{3} \mathrm{O}_{12}$ (ICSD: 100606, monoclinic, $P 2_{1} / \mathrm{a}_{1}$ ) crystalline phase. Fig. 1 (a) shows the diffraction pattern of the $\mathrm{Fe}_{2} \mathrm{Mo}_{3} \mathrm{O}_{12}$ based ceramics. The first diffractogram is relative to $\mathrm{Fe}_{2} \mathrm{Mo}_{3} \mathrm{O}_{12}$ after calcination process and before sintering process (C-FMO). For this sample, only monoclinic $\mathrm{Fe}_{2} \mathrm{Mo}_{3} \mathrm{O}_{12}$ was achieved. For FMO, the results demonstrated that a small fraction (2.2\%) of $\mathrm{Fe}_{2} \mathrm{O}_{3}$ (ICSD: 154190) spurious phase is formed. This behavior was observed for all sintered samples, besides a mass loss in all pellets. Prisco et al. related that $\mathrm{A}_{2} \mathrm{Mo}_{3} \mathrm{O}_{12}$ molybdates has a thermic decomposition in temperatures higher than $700{ }^{\circ} \mathrm{C}$, forming initial oxides used in the reaction [39]. Therefore, all sintered samples were also analyzed by XRPD to examine the crystalline structure after the sintering process. Diffractograms of FMO, FMO-2.5, FMO-5.0 and FMO-7.5 presented the formation of $\mathrm{Fe}_{2} \mathrm{O}_{3}$ (ICSD: 154190, Rhombohedral, R-3c) phase, 
confirming the thermal decomposition of $\mathrm{Fe}_{2} \mathrm{Mo}_{3} \mathrm{O}_{12}$ after the sintering process as described in equation 2.

$$
\mathrm{Fe}_{2} \mathrm{Mo}_{3} \mathrm{O}_{12(\mathrm{~s})} \rightarrow \mathrm{Fe}_{2} \mathrm{O}_{3(\mathrm{~s})}+3 \mathrm{MoO}_{3(\mathrm{~s})}
$$

According to previous results, the $\mathrm{Bi}_{2} \mathrm{O}_{3}-\mathrm{B}_{2} \mathrm{O}_{3}$ sintering aid mix formed amorphous compound after milling process and probably formed a glass phase after sintering. Therefore, no peaks relative to these phases were found in diffractograms.

Rietveld refinement parameters are presented in Table 1. Low values of agreement indices for all samples shows that the Rietveld refinements were satisfactory, with weighted profile Rfactor $\left(R_{W P}\right)$ below $20 \%$ or between 20 and $30 \%$ for samples with two or more phases and $\chi^{2}$ near to unity [40]. Another factor is the similarity between lattice parameters of samples and the pattern of database, which indicates that structure did not change with addition of $\mathrm{Bi}_{2} \mathrm{O}_{3}$ and $\mathrm{B}_{2} \mathrm{O}_{3}$, since $\mathrm{Bi}^{3+}$ can substitute $\mathrm{Fe}^{3+}$ in octahedral site [41]. 

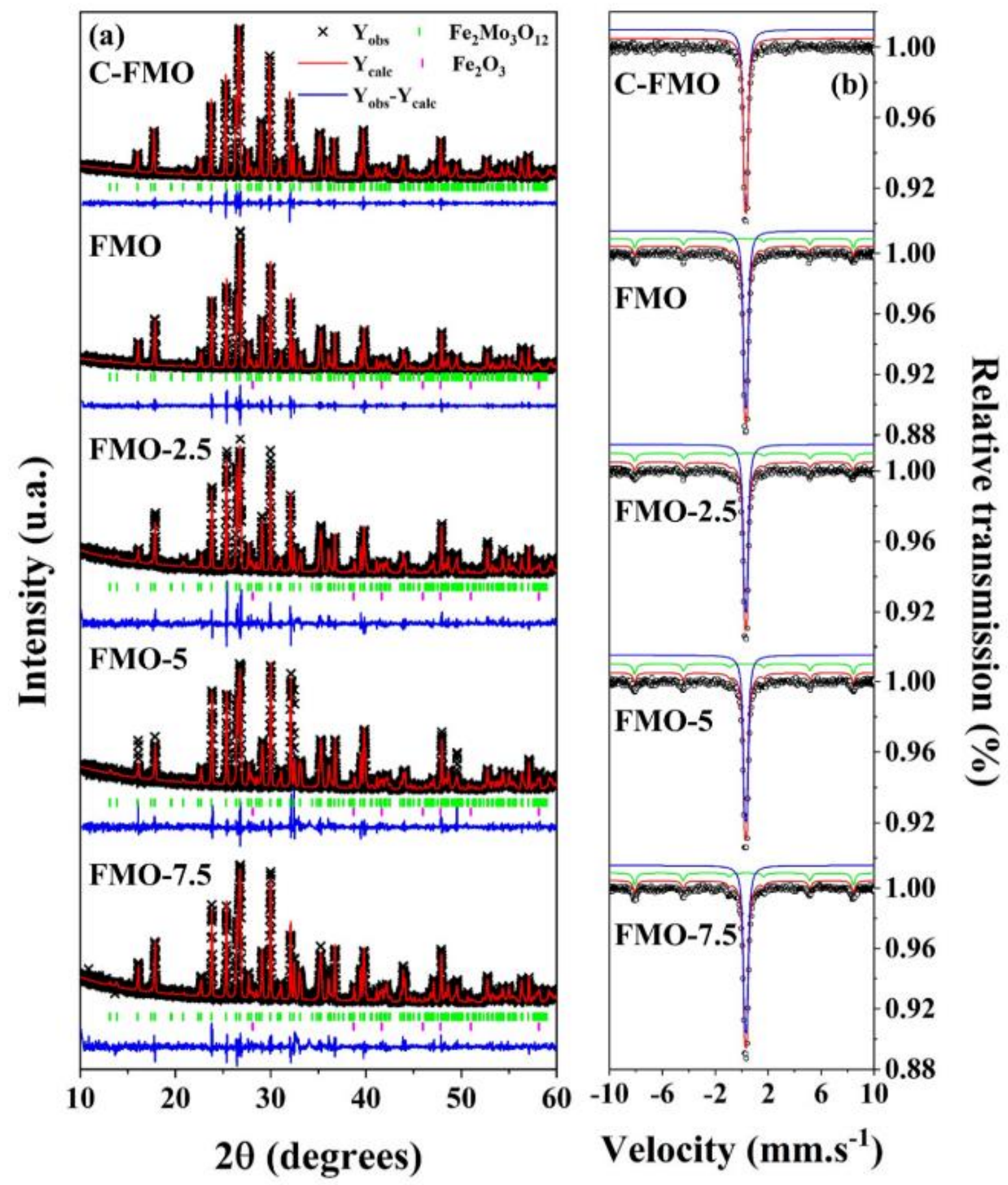

Figure 1: Rietveld refinement of the XRPD (a) with observed $\left(Y_{O b s}\right)$ and calculated $\left(Y_{C a l c}\right)$ intensities and Mössbauer spectra (b) of C-FMO, FMO, FMO-2.5, FMO-5.0 and FMO-7.5. 


\begin{tabular}{|c|c|c|c|c|c|c|c|c|c|c|c|}
\hline \multirow{2}{*}{ Sample } & \multirow{2}{*}{ Phase } & \multirow{2}{*}{$\begin{array}{c}\text { Composition } \\
(\%)\end{array}$} & \multicolumn{7}{|c|}{ Lattice parameters } & \multirow{2}{*}{$\begin{array}{l}R_{W P} \\
(\%)\end{array}$} & \multirow{2}{*}{$\chi^{2}$} \\
\hline & & & a $(\AA)$ & b $(\AA)$ & c $(\AA)$ & $V\left(\AA^{3}\right)$ & $\alpha\left(^{\circ}\right)$ & $\beta\left({ }^{\circ}\right)$ & $\gamma\left({ }^{\circ}\right)$ & & \\
\hline C-FMO & $\mathrm{Fe}_{2} \mathrm{Mo}_{3} \mathrm{O}_{12}$ & 100 & $15.6949(3)$ & $9.2357(1)$ & $18.2226(4)$ & $2157.68(7)$ & 90.0 & $125.228(1)$ & 90.0 & 14.68 & 1.003 \\
\hline \multirow{2}{*}{ FMO } & $\mathrm{Fe}_{2} \mathrm{Mo}_{3} \mathrm{O}_{12}$ & 97.8 & $15.6974(2)$ & $9.2367(1)$ & $18.2230(3)$ & $2158.48(5)$ & 90.0 & $125.222(1)$ & 90.0 & \multirow{2}{*}{15.08} & \multirow{2}{*}{0.973} \\
\hline & $\mathrm{Fe}_{2} \mathrm{O}_{3}$ & 2.2 & $5.4308(7)$ & $5.4308(7)$ & $5.4308(7)$ & $100.73(2)$ & $55.241(6)$ & $55.241(6)$ & $55.241(6)$ & & \\
\hline \multirow{2}{*}{ FMO-2.5 } & $\mathrm{Fe}_{2} \mathrm{Mo}_{3} \mathrm{O}_{12}$ & 88.9 & $15.6987(4)$ & $9.2376(1)$ & $18.2228(5)$ & $2158.67(9)$ & 90.0 & $125.229(1)$ & 90.0 & \multirow{2}{*}{20.67} & \multirow{2}{*}{1.366} \\
\hline & $\mathrm{Fe}_{2} \mathrm{O}_{3}$ & 11.1 & $5.4268(1)$ & $5.4268(1)$ & $5.4268(1)$ & $100.70(3)$ & $55.313(9)$ & $55.313(9)$ & $55.313(9)$ & & \\
\hline \multirow{2}{*}{ FMO-5.0 } & $\mathrm{Fe}_{2} \mathrm{Mo}_{3} \mathrm{O}_{12}$ & 79.64 & $15.6992(4)$ & $9.2374(1)$ & $18.2226(5)$ & $2158.96(9)$ & 90.0 & $125.218(1)$ & 90.0 & \multirow{2}{*}{20.13} & \multirow{2}{*}{1.447} \\
\hline & $\mathrm{Fe}_{2} \mathrm{O}_{3}$ & 20.36 & $5.4292(1)$ & $5.4292(1)$ & $5.4292(1)$ & $100.71(3)$ & $55.266(9)$ & $55.266(9)$ & $55.266(9)$ & & \\
\hline \multirow{2}{*}{ FMO-7.5 } & $\mathrm{Fe}_{2} \mathrm{Mo}_{3} \mathrm{O}_{12}$ & 92.9 & $15.6984(4)$ & $9.2386(1)$ & $18.2272(5)$ & $2159.36(9)$ & 90.0 & $125.230(2)$ & 90.0 & \multirow{2}{*}{18.89} & \multirow{2}{*}{1.242} \\
\hline & $\mathrm{Fe}_{2} \mathrm{O}_{3}$ & 7.1 & $5.4293(6)$ & $5.4293(6)$ & $5.4293(6)$ & $100.74(2)$ & $55.276(5)$ & $55.276(5)$ & $55.276(5)$ & & \\
\hline
\end{tabular}

Table 1: Agreement indices and lattice parameter for $\mathrm{Fe}_{2} \mathrm{Mo}_{3} \mathrm{O}_{12}$ based ceramics. 
The Mössbauer spectra of the samples are shown in Fig. 1 (b). All samples showed a doublet with isomer shift $(\delta)$ near to $0.41 \mathrm{~mm} / \mathrm{s}$, related to paramagnetic $\mathrm{Fe}^{3+}$ ion in high spin state and quadrupole splitting $(\triangle)$ at $0.18 \mathrm{~mm} / \mathrm{s}$, which is assigned to $\left[\mathrm{FeO}_{6}\right]$ sites in $\mathrm{Fe}_{2} \mathrm{Mo}_{3} \mathrm{O}_{12}$ monoclinic phase [42]. Spectra of sintered samples showed a low intensity simple sextet, indicating a magnetically ordered state. The high value of hyperfine field (above $51 \mathrm{~T}$ ), and the values of $\delta$ near $0.37 \mathrm{~mm} / \mathrm{s}$ indicates the presence of $\alpha-\mathrm{Fe}_{2} \mathrm{O}_{3}$ phase [43-45], which were also found in XRPD analysis. The experimental data of hyperfine parameters are presented in Table 2.

Table 2: Hyperfine parameters for $\mathrm{Fe}_{2} \mathrm{Mo}_{3} \mathrm{O}_{12}$ based ceramics.

\begin{tabular}{ccccccc}
\hline Sample & & $\boldsymbol{\delta}(\mathbf{m m} / \mathbf{s})$ & $\boldsymbol{\Delta}(\mathbf{m m} / \mathbf{s})$ & $\boldsymbol{\Gamma}(\mathbf{m m} / \mathbf{s})$ & $\boldsymbol{B}_{H F}(\mathbf{T})$ & Area $(\%)$ \\
\hline C-FMO & Dublet & 0.407 & 0.177 & 0.265 & - & 100 \\
& Dublet & 0.408 & 0.180 & 0.274 & - & 86.5 \\
FMO & Sextet & 0.369 & -0.193 & 0.288 & 51.19 & 13.5 \\
& Dublet & 0.406 & 0.178 & 0.266 & - & 86.0 \\
FMO-2.5 & Sextet & 0.375 & -0.240 & 0.327 & 51.12 & 14.0 \\
& Dublet & 0.407 & 0.180 & 0.260 & - & 84.4 \\
& Sextet & 0.373 & -0.213 & 0.290 & 51.30 & 15.6 \\
& Dublet & 0.408 & 0.179 & 0.269 & - & 81.6 \\
& Sextet & 0.366 & -0.188 & 0.308 & 51.22 & 18.4 \\
\hline
\end{tabular}

FMO-7.5 showed lower quantity of $\mathrm{Fe}_{2} \mathrm{O}_{3}$ than FMO-2.5 and FMO-5.0 in XRPD in the analysis, while in Mössbauer spectroscopy it has the higher concentration of such spurious phase. This is probably due the formation of an amorphous glass phase, composed by $\mathrm{Fe}_{2} \mathrm{O}_{3}-\mathrm{Bi}_{2} \mathrm{O}_{3}-\mathrm{MoO}_{3}$ [46] provided by the thermal decomposition of $\mathrm{Fe}_{2} \mathrm{Mo}_{3} \mathrm{O}_{12}$ [39] during sintering process, which cannot be easily observed in diffractograms.

Fig. 2 shows Raman spectra for FMO samples. The $\mathrm{Fe}_{2} \mathrm{Mo}_{3} \mathrm{O}_{12}$ monoclinic phase belongs to $\mathrm{P} 2{ }_{1} / \mathrm{a}_{1}$ space group with eight molecular formula for unit cell. According to group theory, $\mathrm{Fe}_{2} \mathrm{Mo}_{3} \mathrm{O}_{12}$ has 408 modes in Brillouin zone, three of which are acoustic modes and the rest are optical modes which may be described as irreducible representation $\Gamma_{\mathrm{P}_{1} / \mathrm{a}_{1}}=102 \mathrm{~A}_{\mathrm{g}}+102 \mathrm{~B}_{\mathrm{g}}+101 \mathrm{~A}_{\mathrm{u}}+100 \mathrm{~B}_{\mathrm{u}}$. Only $\mathrm{A}_{\mathrm{g}}$ e $\mathrm{B}_{\mathrm{g}}$ are Raman 
active [30]. For FMO sample, main modes of $\mathrm{Fe}_{2} \mathrm{Mo}_{3} \mathrm{O}_{12}$ structure are observed, which reinforces the data obtained from XRPD analysis. Raman spectra of sintered sample FMO is similar to C-FMO. $\mathrm{Fe}_{2} \mathrm{O}_{3}, \mathrm{Bi}_{2} \mathrm{O}_{3}$ and $\mathrm{B}_{2} \mathrm{O}_{3}$ phases were not assigned due to its bands being overlapped by $\mathrm{Fe}_{2} \mathrm{Mo}_{3} \mathrm{O}_{12}$ 's spectrum. Regions between 700 to $900 \mathrm{~cm}^{-1}$ and 900 to $1200 \mathrm{~cm}^{-1}$ show that some bands keep their shape, intensity and width as it can be seen in Fig. 2. According to Moura et al, [30] the band within 200 to $300 \mathrm{~cm}^{-1}$ correspond to translational motions of $\mathrm{MoO}_{4}$ polyhedra, band from 300 to $500 \mathrm{~cm}^{-1}$ is related to $\mathrm{MoO}_{4}$ tetrahedral bendings. Vibrational modes in 783, 803, 822 and $936 \mathrm{~cm}^{-1}$ are assigned to asymmetrical stretching of Mo-O bond and modes in 968 e $990 \mathrm{~cm}^{-1}$ represents symmetrical stretching of Mo-O bond. All bands and its correlated vibrational modes are presented in Table S1 in Electronic Supplementary Material (ESM).

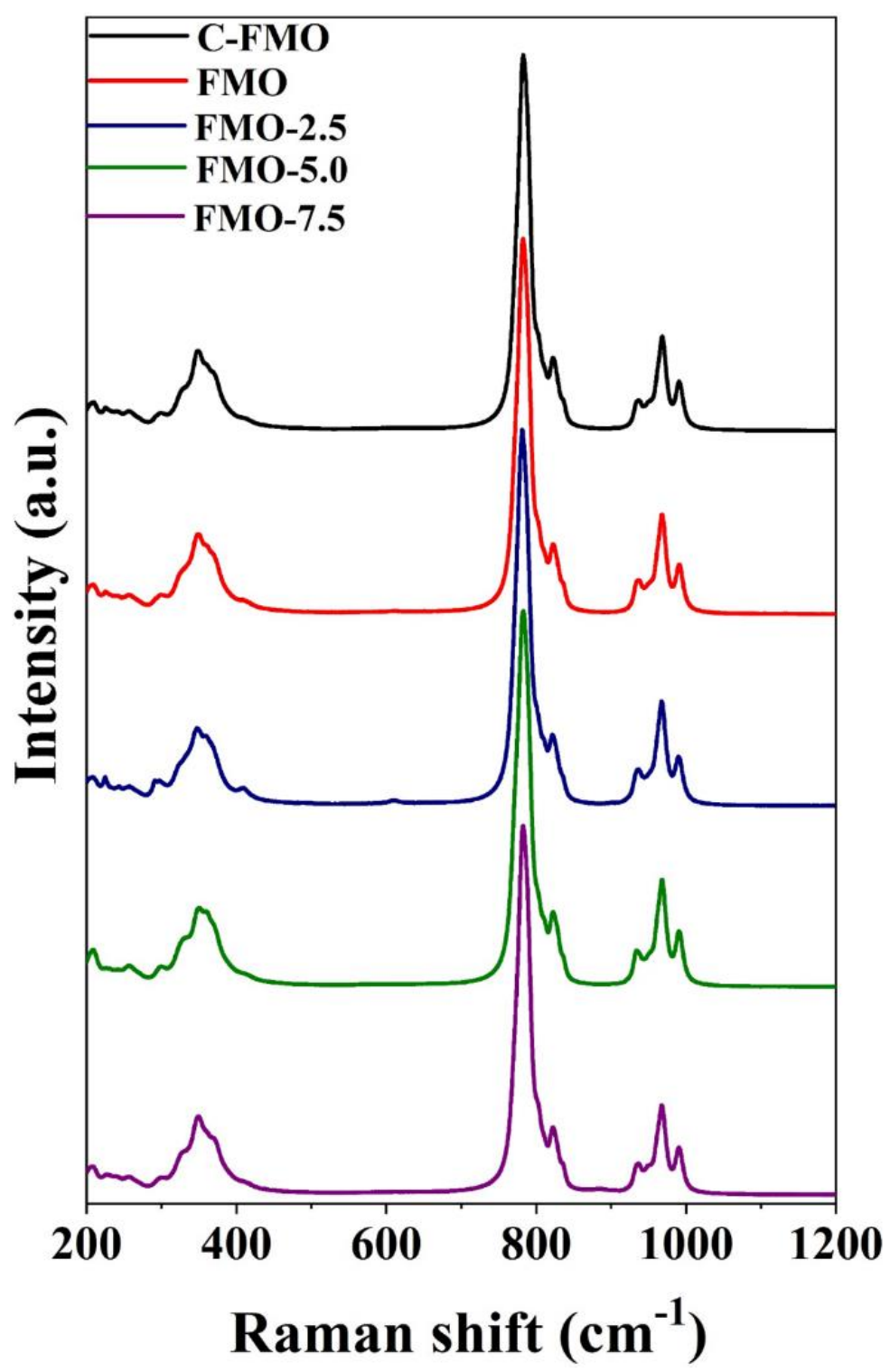


Figure 2: Raman spectra of C-FMO, FMO, FMO-2.5, FMO-5.0 and FMO-7.5.

After sintering process, the pellets were analyzed by SEM at 1000X magnification. Fig. 3 (a) shows the superficial micrograph for FMO. It presents grain size about 3 to $10 \mu \mathrm{m}$ of diameter, while for FMO-2.5, FMO-5.0 and FMO-7.5 (Fig. 3 (b-d)) are between 20 and $30 \mu \mathrm{m}$, as can be seen in the inset of these micrographs. According Tohidifar [33], the sintering aid increases the grain size due the liquid phase flow which promotes the dissolution and diffusion of $\mathrm{Fe}_{2} \mathrm{Mo}_{3} \mathrm{O}_{12}$ grains. Although all pellets showed relative density near to $85 \% \pm 2 \%$, which implies that the addition of $\mathrm{Bi}_{2} \mathrm{O}_{3}-\mathrm{B}_{2} \mathrm{O}_{3}$ as sintering aid does not change the relative density of material in $800{ }^{\circ} \mathrm{C}$ sintering process. According to the scanning utilizing EDS technique (Fig. 3 (e) and Fig. S1 in ESM), the surface of all sintered samples are rich in $\mathrm{Fe}$ and poor in Mo, which reinforces that thermal decomposition during sintering process volatilizing $\mathrm{MoO}_{3}$, leaving the $\mathrm{Fe}_{2} \mathrm{O}_{3}$ on the surface of pellets $[39,47]$. 

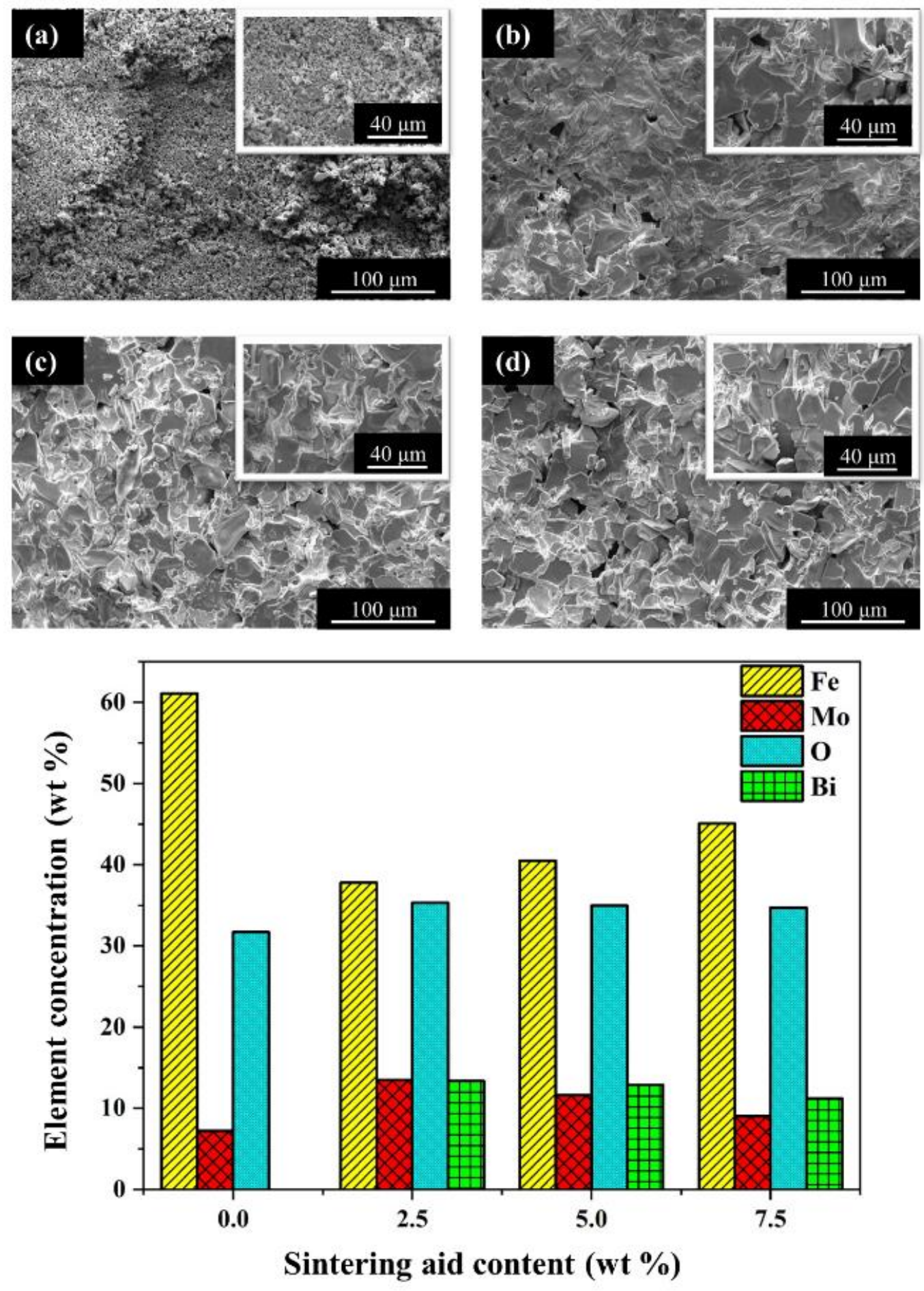

Figure 3: Surface micrograph of (a) FMO, (b) FMO-2.5, (c) FMO-5.0 and (d) FMO-7.5 pellets. Percentage composition in mass ratio versus sintering aid content (e). 
The broken pellets were also analyzed to investigate inner composition (inside the pellet) and compare to the surface. Fig. S2 of ESM presents micrograph for all the samples and they showed grain size near to $40 \mu \mathrm{m}$, higher than those on pellet surface. The scanning using EDS maps are presented in Fig. S3 (ESM) and shows that the concentration of Mo is higher than the ones on surface, which indicates that the pellet's interior does not suffer critical changes in its composition. Table S2 presents the concentration of each element for each sample, for both surface and inside of pellet. Due to the difference on surface and inner composition, EDS analysis of cross section for the FMO sample was made to investigate the inner/surface interface of this material after sintering process and is presented in Fig. 4. Fig. 4 (a) shows the EDS spectrum for pellet surface, while Fig. 4 (b) and Fig. 4 (c) present the EDS spectra for interface and inner, respectively. As can be seen, the amount of Mo is lower on surface than inside the pellet indicating the thermal decomposition of $\mathrm{Fe}_{2} \mathrm{Mo}_{3} \mathrm{O}_{12}$ in $\mathrm{Fe}_{2} \mathrm{O}_{3}$ and $\mathrm{MoO}_{3}$ and then the $\mathrm{MoO}_{3}$ volatilization at $700{ }^{\circ} \mathrm{C}$ on the surface of the pellet $[39,47-49]$.

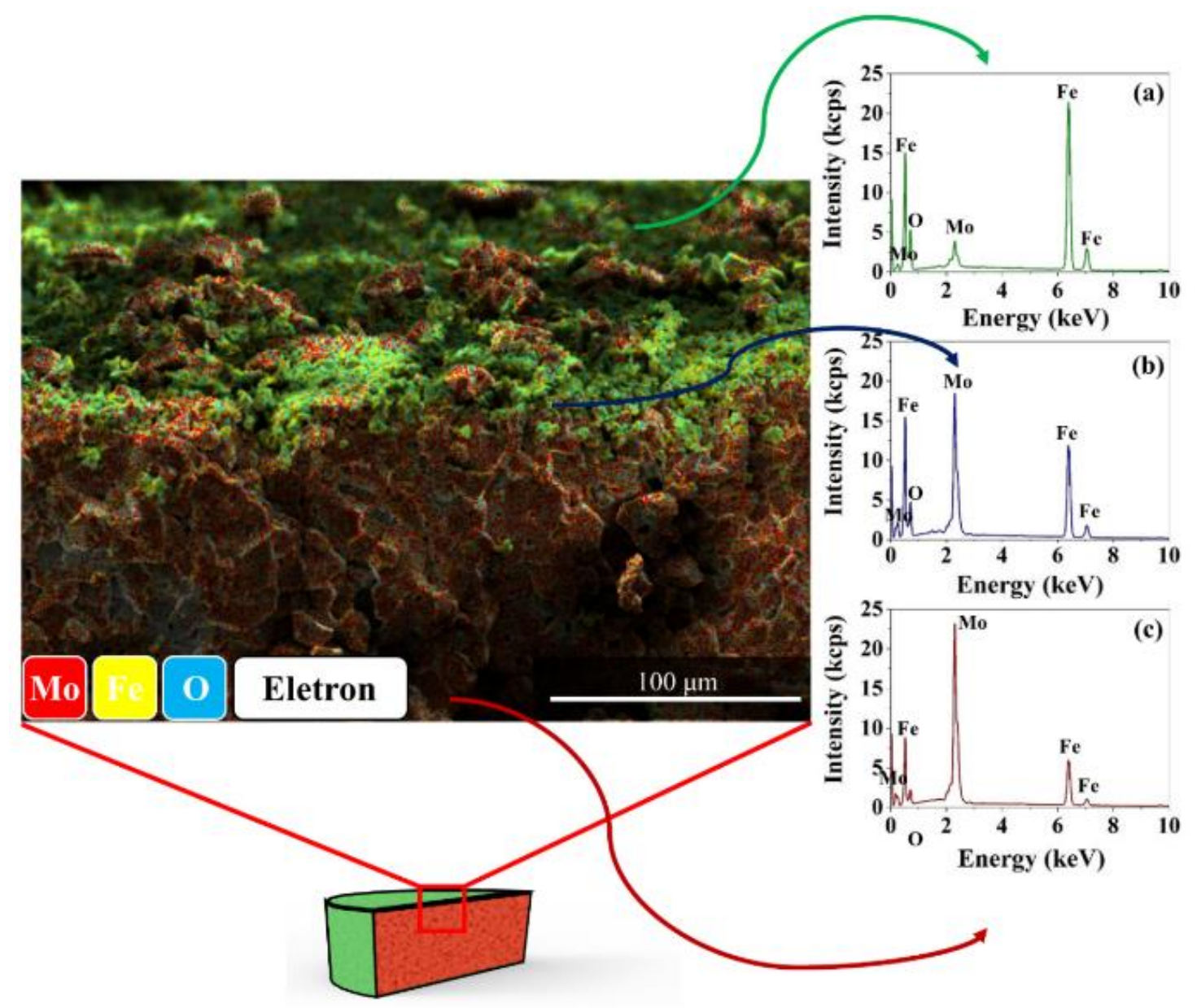

Figure 4: Cylindrical pellet scheme and EDS spectra of different areas. (a) Surface, (b) surface/inner interface and (c) inner. 
The results of all structural and morphological characterization allow us to affirm that small part of $\mathrm{Fe}_{2} \mathrm{Mo}_{3} \mathrm{O}_{12}$ decomposes thermally in $\mathrm{MoO}_{3}$ and $\mathrm{Fe}_{2} \mathrm{O}_{3}$. Superficial $\mathrm{MoO}_{3}$ volatilize and left surface rich in $\mathrm{Fe}_{2} \mathrm{O}_{3}$ (observed in mass loss after sintering process and EDS analysis), while inner $\mathrm{MoO}_{3}$ may form an amorphous glass phase with $\mathrm{Fe}_{2} \mathrm{O}_{3}$ and $\mathrm{Bi}_{2} \mathrm{O}_{3}[46]$.

Fig. 5 shows the imaginary part of impedance (Z”) spectra and temperature dependency $\left(220-260^{\circ} \mathrm{C}\right)$ for the samples. For FMO (Fig. 5 (a)), FMO-2.5 (Fig. 5 (b)) and FMO5.0 (Fig. 5 (c)) there is a peak about $1 \mathrm{MHz}$, while for FMO-7.5 (Fig. 5 (d)) this peak appears near to $100 \mathrm{kHz}$. For the maximum of peak observed in Z" spectrum is observed a shift for higher values with increasing of the temperature what can be related to the relaxation process thermally activated [50]. As can be seen in insets of Fig. 5, the normalized peaks shift to regions of higher frequency.
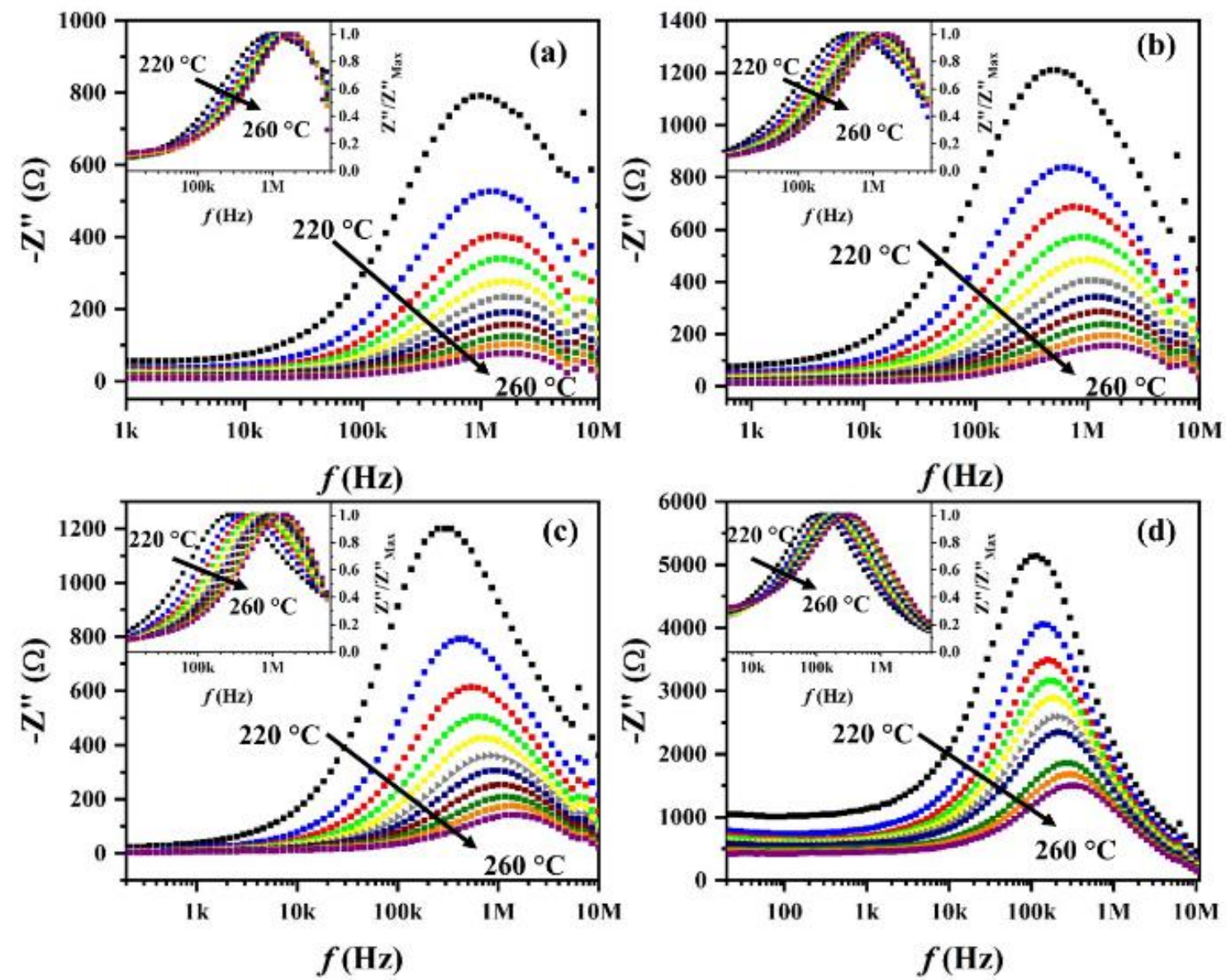

Figure 5: Z" spectra of (a) FMO, (b) FMO-2.5, (c) FMO-5.0 and (d) FMO-7.5. Normalized $Z$ ”' spectrum (inset). 
The shift is thermally activated and may be described by Arrhenius' equation:

$$
\ln f_{\text {Max }}=\ln f_{0}-\frac{E_{a}}{k_{b} T}
$$

where $f_{\text {Max }}$ is the frequency when $Z$ " has a maximum value, $f_{\mathrm{o}}$ is the pre-exponential term, $E_{a}$ is the activation energy of the process, $K_{b}$ is the Boltzmann constant and $T$ is temperature [50]. The $E_{a}$ are determined by the angular coefficient of linear curves in Fig. 6.

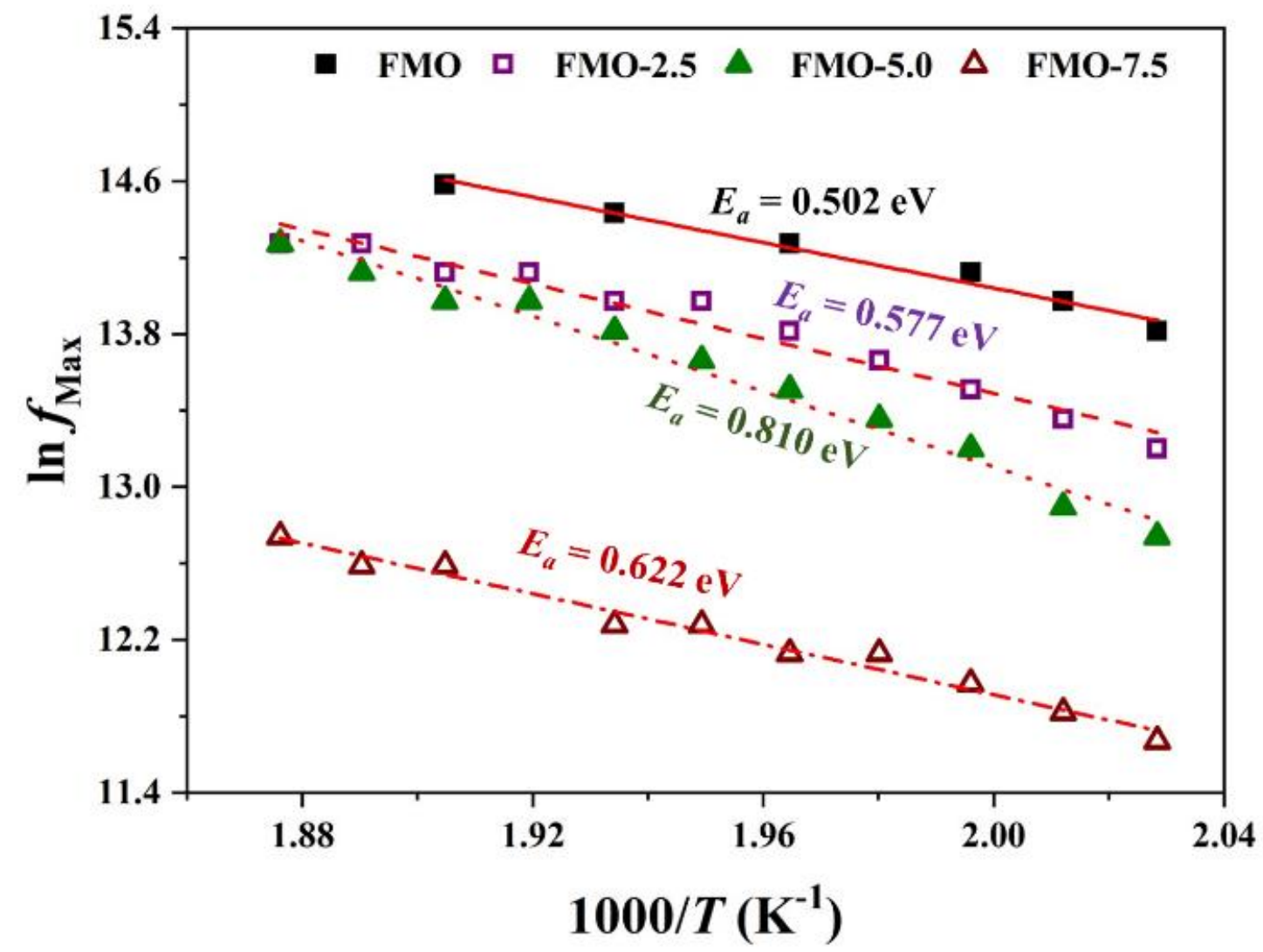

Figure 6: Activation energy of FMO, FMO-2.5, FMO-5.0 and FMO-7.5.

The addition of sintering aid has a direct influence on this process. The $E_{a}$ increases with rising in sintering aid addition, except for FMO-7.5. This increase is probably due to the higher concentration of $\mathrm{Fe}_{2} \mathrm{O}_{3}$ spurious phase [51] demonstrated in XRPD and Mössbauer study. FMO presented the lowest energy of $0.502 \mathrm{eV}$ while FMO-5.0 presented energy of $0.810 \mathrm{eV}$. These $E_{a}$ values are controlled by $\mathrm{Bi}_{2} \mathrm{O}_{3}$ and $\mathrm{Fe}_{2} \mathrm{O}_{3}$ phases formed or added in these composites. 
Nyquist's plots ( $Z$ " versus $Z^{\prime}$ ) were also analyzed. The spectra presented deformed semicircles in relation to $Z$ " axis, corresponding to non-Debye model [52]. The behavior of the ceramic material may be described as resistor-capacitor (R-C), equivalent circuit describing the electric response of grain, grain boundary and electrode effect. As the capacitive contribution does not represent an ideal behavior, the capacitor is substituted by a constant phase element $(\mathrm{CPE})$. The $\mathrm{CPE}$ impedance $\left(\mathrm{Z}_{\mathrm{CPE}}\right)$ is described as the following equation [50]:

$$
\mathrm{Z}_{\mathrm{CPE}}=\frac{1}{\mathrm{Q}(\mathrm{j} \omega)^{\mathrm{n}}}
$$

where $\mathrm{Q}$ is a proportional factor, $\omega$ is the angular frequency and $n$ is an empirical exponent with values between 0 (ideal resistor) and 1 (ideal capacitor). All samples were fitted by a non-linear function and are presented in Fig. 7. $R_{g}, R_{g b}$ and $R_{e}$ are grain resistance, grain boundary resistance and electrode resistance, respectively, while $\mathrm{CPE}_{\mathrm{g}}$, $\mathrm{CPE}_{\mathrm{gb}}$ and $\mathrm{CPE}_{\mathrm{e}}$ are grain constant phase element, grain boundary constant phase element and electrode constant phase element. Resistive and capacitive contributions of each component (grain, grain boundary and electrode) of the FMO, FMO-2.5, FMO-5.0 and FMO-7.5 are presented in Table S3, S4, S5 and S6 of ESM, respectively. 

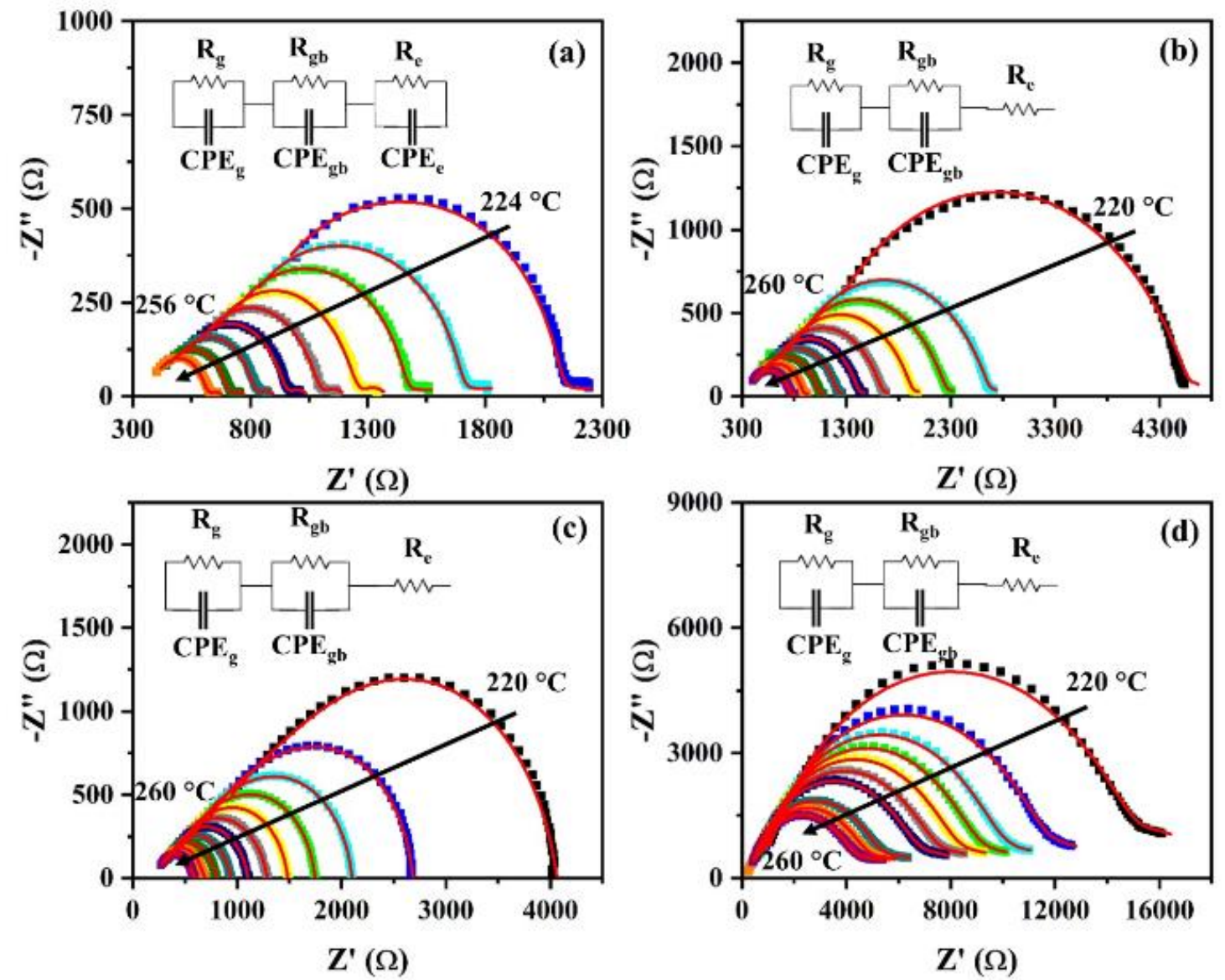

Figure 7: -Z” versus Z' of (a) FMO, (b) FMO-2.5, (c) FMO-5.0 and (d) FMO-7.5

As described previously in $Z$ " spectra, the resistive contribution of grain, grain boundary and electrode effect decrease with temperature increasing. Grain and electrode are predominantly capacitive due to the fitted parameter $n$ (deviation of ideal capacitance) for CPE element with increasing of the temperature [53].

The addition of sintering aid makes the electrode contribution purely resistive, eliminating the capacitive. Moreover, for all samples, the increasing of temperature leads to the decreasing of $n$ value for grain boundary contribution, indicating an increasing in resistive contribution of this element. Thermal stability of capacitance (TCC) was also determined for all samples using the relation described in Eq. 5 [54].

$$
T C C=\frac{C_{100}-C_{25}}{C_{25} \cdot(100-25)} \cdot 10^{6}
$$


Where $\mathrm{C}_{100}$ and $\mathrm{C}_{25}$ are the capacitance in 100 and $25^{\circ} \mathrm{C}$ respectively. Table 3 presents the TCC in $100 \mathrm{~Hz}, 1 \mathrm{kHz}, 10 \mathrm{kHz}$ and $1 \mathrm{MHz}$ frequencies.

Table 3: TCC of FMO, FMO-2.5, FMO-5.0 e FMO-7.5.

\begin{tabular}{ccccc}
\hline & \multicolumn{4}{c}{$\mathrm{TCC}\left(\mathrm{ppm} .{ }^{\circ} \mathrm{C}^{-1}\right)$} \\
\cline { 2 - 5 } Composition & $100 \mathrm{~Hz}$ & $1 \mathrm{kHz}$ & $10 \mathrm{kHz}$ & $1 \mathrm{MHz}$ \\
\hline FMO & 2986.91 & 4966.44 & -441.12 & -1631.75 \\
FMO-2.5 & 403468.83 & 210034.36 & 71681.96 & 63636.36 \\
FMO-5.0 & 5637.25 & 4444.44 & -1782.05 & -1956.45 \\
FMO-7.5 & 20747.38 & 18966.13 & -1821.25 & -2099.24 \\
\hline
\end{tabular}

FMO-2.5 presents the highest value of TCC for all frequencies. FMO-7.5 is unstable at low frequencies, presenting 20747.38 and $18966.13 \mathrm{ppm} .{ }^{\circ} \mathrm{C}^{-1}$ at $100 \mathrm{~Hz}$ and $1 \mathrm{kHz}$ respectively, but is stable at high frequencies. Although FMO, FMO-5.0 and FMO-7.5 presented low value of TCC, at $10 \mathrm{kHz}$ and $1 \mathrm{MHz}$. According to IEC/EN 60384-8/21 and EIA-RS-198, FMO, FMO-2.5 and FMO-7.5 are potential to be applied as class 1 capacitor at $10 \mathrm{kHz}$. These ceramics were also analyzed in a microwave frequency range. The temperature coefficient of resonant frequency $\left(\tau_{f}\right)$ was determined using the relation described in Eq. 6 [54].

$$
\tau_{f}=\frac{f_{80}-f_{25}}{f_{25} \cdot(80-25)} \cdot 10^{6}
$$

Where $f_{80}$ and $f_{25}$ are the resonant frequency at $80^{\circ} \mathrm{C}$ and $25^{\circ} \mathrm{C}$, respectively. Table 4 presents the microwave dielectric properties for all samples. Table 4 presents the microwave dielectric properties for all samples. The addition of sintering aid does not imply many changes in microwave dielectric properties of bulks. FMO-2.5 presented the higher $\varepsilon_{r}$ value (9.70) among the samples. Furthermore, FMO based ceramics have $\varepsilon_{r}$ between 9.3 to 9.7 , near of $\mathrm{Al}_{2} \mathrm{O}_{3}\left(\varepsilon_{r}=9.8\right)$, one of the most important oxides used in industry [55]. All compositions showed low values of $\tan \delta$, and FMO-2.5 presented the smallest value $\left(6.52 \times 10^{-4}\right)$. This phenomenon can be related to the liquid phase of sintering aid between grain interstice [7]. The greatest dielectric loss of FMO can be 
related to the extrinsic loss due to the smaller grains on the surface of the bulk, as can be seen by SEM images [56]. Although all compositions showed a low dielectric loss, which is required for some applications [5]. Moreover, all the composition presented high values of $Q \times f$, and the FMO-2.5 is the one that presented the highest value of 16054.24 GHz, which shows its potential use in microwave devices. $\tau_{f}$ values increase in modulus with increasing sintering aid content, except for FMO-7.5 bulk. FMO and FMO-7.5 showed the lower values of $\tau_{f}$, probably due to the lower quantity of $\mathrm{Fe}_{2} \mathrm{O}_{3}$ as a spurious phase which presents a $\tau_{f}$ of $-66.64 \mathrm{ppm} .{ }^{\circ} \mathrm{C}^{-1}$ [51]. However, FMO-2.5 and FMO-5.0 presented the highest values of $\tau_{f}$. This phenomenon is probably related to the high concentration of $\mathrm{Fe}_{2} \mathrm{O}_{3}$, as it was quantified by XRPD analysis [51, 57].

Table 4: Dielectric properties of FMO, FMO-2.5, FMO-5.0, and FMO-7.5 in the microwave range.

\begin{tabular}{ccccc}
\hline Composition & $\boldsymbol{\varepsilon}_{\boldsymbol{r}}$ & $\boldsymbol{t a n} \boldsymbol{\delta}$ & $\boldsymbol{Q \boldsymbol { x } \boldsymbol { f } ( \mathbf { G H z } )}$ & $\boldsymbol{\tau}_{\boldsymbol{f}}\left(\mathbf{p p m} .^{\circ} \mathbf{C}^{-1}\right)$ \\
\hline FMO & 9.33 & $9.45 \times 10^{-4}$ & 14132.35 & -6.55 \\
FMO-2.5 & 9.70 & $6.52 \times 10^{-4}$ & 16054.24 & -30.08 \\
FMO-5.0 & 9.56 & $6.98 \times 10^{-4}$ & 14691.35 & -62.99 \\
FMO-7.5 & 9.49 & $7.15 \times 10^{-4}$ & 14439.76 & -4.35 \\
\hline
\end{tabular}

Near-zero $\tau_{f}$ is a very desirable property for resonators and substrates. Recently some researches were taking original strategies to achieve this goal. Castro and coworkers investigated $\left(\mathrm{Ba}_{2} \mathrm{CoNbO}_{6}\right)_{1-\mathrm{x}}-\left(\mathrm{CaTiO}_{3}\right)_{\mathrm{x}}$ composite and reached near-zero $\tau_{f}$ at $\mathrm{x}=0.37$ [58]. Oliveira investigated the effect of $\mathrm{CaTiO}_{3}$ addition in thermal stability of the $\mathrm{BiVO}_{4}$ matrix [59] and Paiva investigated the $\mathrm{Y}_{3} \mathrm{Fe}_{5} \mathrm{O}_{12}-\mathrm{CaTiO}_{3}$ composite and determined that near-zero $\tau_{f}$ composition [60]. The FMO and FMO-7.5 bulks showed $\tau_{f}$ values of -6.55 and $-4.35 \mathrm{ppm} .{ }^{\circ} \mathrm{C}^{-1}$, respectively. Also, they are characterized as nearzero $\tau_{f}$, since their values are smaller than $\pm 10 \mathrm{ppm} .{ }^{\circ} \mathrm{C}^{-1}$.

\section{Conclusion}


The solid-state route showed an optimum way to produce the $\mathrm{Fe}_{2} \mathrm{Mo}_{3} \mathrm{O}_{12}$ monoclinic phase at $650{ }^{\circ} \mathrm{C}$, which was verified by XRPD, Mössbauer, and Raman spectroscopy. The sintering process at $800{ }^{\circ} \mathrm{C}$ was effective in producing dense solids. The SEM images associated with EDS spectra show that the surface of pellets is rich in Fe because of the thermal decomposition of $\mathrm{Fe}_{2} \mathrm{Mo}_{3} \mathrm{O}_{12}$ at high temperatures and $\mathrm{MoO}_{3}$ volatilization. Although the superficial decomposition, the inner structure is preserved, and presence of $\mathrm{Bi}_{2} \mathrm{O}_{3}-\mathrm{B}_{2} \mathrm{O}_{3}$ allows the growth of superficial grains. Moreover, $\mathrm{Bi}_{2} \mathrm{O}_{3}$ $\mathrm{B}_{2} \mathrm{O}_{3}$ sintering aid may prevent higher Mo volatilization, since its content stay close to $7.5 \%$. Nyquist diagrams were observed in a temperature range of $220^{\circ} \mathrm{C}$ to $260{ }^{\circ} \mathrm{C}$. The grain, grain boundary, and electrode effect contributions were analyzed using an equivalent circuit. Three contributions were obtained from R-CPE to the FMO, while for samples with sintering aid, the capacitive contribution of the electrode vanished away. Furthermore, the $\mathrm{Bi}_{2} \mathrm{O}_{3}-\mathrm{B}_{2} \mathrm{O}_{3}$ mix increases the resistive contribution of grain in all-ceramic samples compared to FMO. The FMO, FMO-5.0 and FMO-7.5 presented low values of TCC ranging -441.12 to $-1824.25 \mathrm{ppm} .{ }^{\circ} \mathrm{C}^{-1}$ and -1631.75 to -2099.24 at $10 \mathrm{kHz}$ and $1 \mathrm{MHz}$ respectively. Microwave characterization presented $\varepsilon_{r}$ within 9.3 and 9.7, and all compositions presented tan $\delta$ at the magnitude order of $10^{-4}$ and $Q \times f$ values above $14000 \mathrm{GHz}$. This implies that they all have the potential to be applied as microwave devices, such as microstrip antenna substrate or dielectric resonator antennas. Moreover, FMO and FMO-7.5 have near-zero $\tau_{f}\left(\right.$ smaller than $\pm 10 \mathrm{ppm} /{ }^{\circ} \mathrm{C}$ ), making them suitable candidates for dielectric resonator antenna.

\section{Acknowledgements}

We gratefully acknowledge the financial support of the following Brazilian agencies for scientific and technological development: CNPq (408790/2016-4), CAPES (Finance Code 001), and Funcap (PNE-0112-00048.01.00/16). In addition, the authors are also grateful for the Central Analítica-UFC/CT-INFRA/MCTI-SISNANO/PróEquipamentos, for providing the equipment and technical support for the experiments involving SEM, Laboratório de Difração de raios-X (UFC), and Laboratório de Espectroscopia Vibracional e Microscopia (UFC).

\section{Declaration of competing interest}


The authors declare that they have no known competing financial interests or personal relationships that could have appeared to influence the work reported in this paper.

\section{References.}

[1] Peng H, Ren H, Dang M, et al. Novel high dielectric constant and low loss PTFE/CNT composites. Ceram Int 2018, 14:16556-16560.

[2] Ren J, Bi K, Fu X, Peng Z. Novel $\mathrm{Bi}_{2} \mathrm{O}_{3}$-added $\mathrm{Al}_{2} \mathrm{Mo}_{3} \mathrm{O}_{12}$ composite microwave dielectric ceramics for ULTCC applications. J Alloys Compd 2020, 823:153867.

[3] Ren $\mathrm{H}, \mathrm{Xie} \mathrm{T}, \mathrm{Wu} \mathrm{Z}$, et al. Crystal structure, phase evolution and dielectric properties in the $\mathrm{Li}_{2} \mathrm{ZnTi}_{3} \mathrm{O}_{8}-\mathrm{SrTiO}_{3}$ system as temperature stable high-Q material. J Alloys Compd 2019, 797:18-25.

[4] Feng ZB, Tao BJ, Wang WF, et al. Sintering behavior and microwave dielectric properties of $\mathrm{Li}_{4} \mathrm{Mg}_{3}\left[\mathrm{Ti}_{0.8}\left(\mathrm{Mg}_{1 / 3} \mathrm{Ta}_{2 / 3}\right)_{0.2}\right]_{2} \mathrm{O}_{9}$ ceramics with $\mathrm{LiF}$ additive for LTCC applications. J Alloys Compd 2020, 822:153634.

[5] Sebastian MT, Wang H, Jantunen H. Low temperature co-fired ceramics with ultra-low sintering temperature: a review. Curr Opin Solid State Mater Sci 2016, 20:151-170.

[6] Weng Z, AminiRastabi H, Xiong Z, Xue H. Effects of the $\mathrm{Bi}_{2} \mathrm{O}_{3}-\mathrm{SiO}_{2}$ addition on the sintering behavior and microwave dielectric properties of $\mathrm{Zn}_{1.8} \mathrm{SiO}_{3.8}$ ceramics. J Alloys Compd 2017, 725:1063-1068.

[7] Zhang P, Liao J, Zhao Y, et al. Microstructures and dielectric properties of low permittivity $\mathrm{SrCuSi}_{4} \mathrm{O}_{10}-\mathrm{Bi}_{2} \mathrm{O}_{3}$ ceramics for LTCC applications. J Mater Sci Mater Electron 2017, 28:4946-4950.

[8] Li T, Segawa H, Ohashi N. Sintering behavior and dielectric properties of $\mathrm{BaTiO}_{3}$ added with $\mathrm{BaO}-\mathrm{Bi}_{2} \mathrm{O}_{3}-\mathrm{B}_{2} \mathrm{O}_{3}$ glass phase. Ceram Int 2018, 44:13004-13010.

[9] Cao R, Wu L, Di X, et al. A WLED based on LuAG:Ce ${ }^{3+}$ PiG coated red-emitting $\mathrm{K}_{2} \mathrm{SiF}_{6}: \mathrm{Mn}^{4+}$ phosphor by screen-printing. Opt Mater (Amst) 2017, 70:92-98.

[10] Chen S, Li W, Zhu D-G. Sintering behaviors, phases, and dielectric properties of MO- $\mathrm{TeO}_{2}-\mathrm{V}_{2} \mathrm{O}_{5}(\mathrm{M}=\mathrm{Ca}, \mathrm{Sr}, \mathrm{Ba})$ ultralow temperature ceramics. Mater Res Bull 
2018, 101:29-38.

[11] Masturah M, Norezan I, Yahya AK, et al Effect of $\mathrm{V}_{2} \mathrm{O}_{5}-\mathrm{TeO}_{2}$ Glass Addition on Dielectric Properties of $\mathrm{CaCu}_{3} \mathrm{Ti}_{4} \mathrm{O}_{12}$ Ceramics Prepared by Solid State Method. Trans Indian Inst Met 2013, 66:325-328.

[12] Arantes VL. Sintering and microwave properties of zirconium tin titanate doped with select oxides. J Mater Eng Perform, 2012 21:1777-1784.

[13] Guan S, Yang H, Zhao Y, Zhang R. Effect of $\mathrm{Li}_{2} \mathrm{CO}_{3}$ addition in $\mathrm{BiFeO}_{3}-\mathrm{BaTiO}_{3}$ ceramics on the sintering temperature, electrical properties and phase transition. $J$ Alloys Compd 2018, 735:386-393.

[14] Kim KI, Kim HS, Yun JW. Effects of zinc nitrate as a sintering aid on the electrochemical characteristics of $\mathrm{Sr}_{0.92} \mathrm{Y}_{0.08} \mathrm{TiO}_{3-\delta}$ and $\mathrm{Sr}_{0.92} \mathrm{Y}_{0.08} \mathrm{Ti}_{0.6} \mathrm{Fe}_{0.4} \mathrm{O}_{3-\delta}$ anodes. Ceram Int 2018, 44:4262-4270.

[15] Zhang G, Wang $\mathrm{H}$, Guo J, et al. Ultra-low sintering temperature microwave dielectric ceramics based on $\mathrm{Na}_{2} \mathrm{O}-\mathrm{MoO}_{3}$ binary system. J Am Ceram Soc 2015, 98:528-533.

[16] Dhanya J, Suresh EK, Naveenraj R, Ratheesh R. Synthesis and characterization of $\mathrm{Na}_{5} \mathrm{M}\left(\mathrm{MoO}_{4}\right)_{4}(\mathrm{M}=\mathrm{Y}, \mathrm{Yb})$ microwave ceramics for ULTCC applications. Ceram Int 2018, 44:6699-6704.

[17] Li H, Huang Z, Cheng L, et al. Structure and dielectric properties of novel low temperature co-fired $\mathrm{Bi}_{2} \mathrm{O}_{3}-\mathrm{RE}_{2} \mathrm{O}_{3}-\mathrm{MoO}_{3}(\mathrm{RE}=\mathrm{Pr}, \mathrm{Nd}, \mathrm{Sm}$, and $\mathrm{Yb})$ based microwave ceramics. Ceram Int 2017, 43:4570-4575.

[18] Zhou D, Randall CA, Wang $\mathrm{H}$, et al. Microwave dielectric ceramics in $\mathrm{Li}_{2} \mathrm{O}-$ $\mathrm{Bi}_{2} \mathrm{O}_{3}-\mathrm{MoO}_{3}$ system with ultra-low sintering temperatures. J Am Ceram Soc 2010, 93:1096-1100.

[19] Zuo R, Xu Y, Shi M, et al. A new series of low-temperature cofirable $\mathrm{Li}_{3} \mathrm{Ba}_{2} \mathrm{La}_{3(1-}$ ${ }_{\mathrm{x})} \mathrm{Y}_{3 \mathrm{x}}\left(\mathrm{MoO}_{4}\right)_{8}$ microwave dielectric ceramics. J Eur Ceram Soc 2018, 38:46774681 .

[20] Kähäri H, Teirikangas M, Juuti J, Jantunen H. Dielectric properties of lithium molybdate ceramic fabricated at room temperature. J Am Ceram Soc 2014, 97:3378-3379. 
[21] Joseph N, Varghese J, Siponkoski T, et al. Glass-free $\mathrm{CuMoO}_{4}$ ceramic with excellent dielectric and thermal properties for ultralow temperature cofired ceramic applications. ACS Sustain Chem Eng 2016, 4:5632-5639.

[22] Pang L-X, Zhou D, Cai C-L, Liu W-G (2013) Infrared spectroscopy and microwave dielectric properties of ultra-low temperature firing $\left(\mathrm{K}_{0.5} \mathrm{La}_{0.5}\right) \mathrm{MoO}_{4}$ ceramics. Mater Lett 92:36-38

[23] Ren J, Bi K, Fu X, Peng Z. Novel $\mathrm{Al}_{2} \mathrm{Mo}_{3} \mathrm{O}_{12}$-based temperature-stable microwave dielectric ceramics for LTCC applications. J Mater Chem C 2018, 6:11465-11470.

[24] Joseph N, Varghese J, Teirikangas M, et al. Ultra-low sintering temperature ceramic composites of $\mathrm{CuMoO}_{4}$ through $\mathrm{Ag}_{2} \mathrm{O}$ addition for microwave applications. Compos Part B Eng 2018, 141:214-220.

[25] Romao CP, Miller KJ, Johnson MB, et al. Thermal, vibrational, and thermoelastic properties of $\mathrm{Y}_{2} \mathrm{Mo}_{3} \mathrm{O}_{12}$ and their relations to negative thermal expansion. Phys Rev B 2014, 90:24305.

[26] Romao CP, Donegan SP, Zwanziger JW, White MA. Relationships between elastic anisotropy and thermal expansion in $\mathrm{A}_{2} \mathrm{Mo}_{3} \mathrm{O}_{12}$ materials. Phys Chem Chem Phys 2016, 18:30652-30661.

[27] Tamas V, Moats JL, Ushakov SV. Thermochemistry of $\mathrm{A}_{2} \mathrm{M}_{3} \mathrm{O}_{12}$ negative thermal expansion materials. J Mater Res 2007, 22:2512.

[28] Mary TA, Sleight AW. Bulk thermal expansion for tungstate and molybdates of the type $\mathrm{A}_{2} \mathrm{M}_{3} \mathrm{O}_{12}$. J Mater Res 1999, 14:912-915.

[29] Li ZY, Song WB, Liang EJ. Structures, Phase Transition, and Crystal Water of $\mathrm{Fe}_{2-\mathrm{x}} \mathrm{Y}_{\mathrm{x}} \mathrm{Mo}_{3} \mathrm{O}_{12}$. J Phys Chem C 2011, 115:17806-17811.

[30] Moura JVB, Pinheiro GS, Freire PTC, et al. High-pressure Raman scattering on $\mathrm{Fe}_{2}\left(\mathrm{MoO}_{4}\right)_{3}$ microcrystals obtained by a hydrothermal method. Vib Spectrosc 2016, 87:88-93.

[31] Tummala RR. Ceramic and glass-ceramic packaging in the 1990s. J Am Ceram Soc 1991, 74:895-908. 
[32] Neelakantan UA, Kalathil SE, Ratheesh R. Structure and microwave dielectric properties of ultralow-temperature cofirable $\mathrm{BaV}_{2} \mathrm{O}_{6}$ ceramics. Eur J Inorg Chem 2015, 2015:305-310.

[33] Tohidifar MR. Improving sintering behavior of $\mathrm{MWCNT} / \mathrm{BaTiO}_{3}$ ceramic nanocomposite with $\mathrm{Bi}_{2} \mathrm{O}_{3}-\mathrm{B}_{2} \mathrm{O}_{3}$ addition. Ceram Int 2018, 44:3699-3706.

[34] Le S, Zhang J, Zhu X, et al. Sintering and electrochemical performance of $\mathrm{Y}_{2} \mathrm{O}_{3}$ doped barium zirconate with $\mathrm{Bi}_{2} \mathrm{O}_{3}$ as sintering aids. J Power Sources 2013, 232:219-223.

[35] Pan Y, Yin J, Zuo K, et al. The sintering behavior and mechanical properties of $\mathrm{CaSiO}_{3}$ bioceramics with $\mathrm{B}_{2} \mathrm{O}_{3}$ addition. Ceram Int 2016, 42:9222-9226.

[36] dos Santos CM, Martins AFN, Costa BC, et al. Synthesis of FeNi Alloy Nanomaterials by Proteic Sol-Gel Method: Crystallographic, Morphological, and Magnetic Properties. J Nanomater 2016, 2016.

[37] Hakki BW, Coleman PD. A dielectric resonator method of measuring inductive capacities in the millimeter range. IRE Trans Microw Theory Tech 1960, 8:402410.

[38] Silva MAS, Fernandes TSM, Sombra ASB. An alternative method for the measurement of the microwave temperature coefficient of resonant frequency $\left(\tau_{f}\right) . J$ Appl Phys 2012, 112:74106.

[39] Prisco LP, Pontón PI, Paraguassu W, et al. Near-zero thermal expansion and phase transition in $\mathrm{In}_{0.5}(\mathrm{ZrMg})_{0.75} \mathrm{Mo}_{3} \mathrm{O}_{12}$. J Mater Res 2016, 31:3240.

[40] Deng F, Lin X, He Y, et al. Quantitative phase analysis by the Rietveld method for Forensic science. J Forensic Sci 2015, 60:1040-1045.

[41] Cheng YZ, Wu MM, Peng J, et al. Structural studies of Fe doped $\mathrm{Bi}_{2} \mathrm{Mo}_{3} \mathrm{O}_{12}$ catalysts using neutron and X-ray powder diffraction. Mater Technol 2008, 23:33-38.

[42] Jirak Z, Salmon R, Fournes L, et al. Magnetic and Mössbauer resonance investigations of the weak ferrimagnet iron molybdate $\left(\mathrm{Fe}_{2}\left(\mathrm{MoO}_{4}\right)_{3}\right)$. Inorg Chem 1982, 21:4218-4223. 
[43] Yoon S. Preparation and physical characterizations of superparamagnetic maghemite nanoparticles. J Magn 2014, 19:323-326.

[44] Sharma VK, Klingelhofer G, Nishida T. Mössbauer spectroscopy: applications in chemistry, biology, and nanotechnology. John Wiley \& Sons, 2013.

[45] Bashir AKH, Furqan CM, Bharuth-Ram K, et al. Structural, optical and Mössbauer investigation on the biosynthesized $\alpha-\mathrm{Fe}_{2} \mathrm{O}_{3}$ : study on different precursors. Phys E Low-dimensional Syst Nanostructures 2019, 111:152-157.

[46] Iordanova R, Dimitriev Y, Dimitrov V, et al. Glass formation and structure in the system $\mathrm{MoO}_{3}-\mathrm{Bi}_{2} \mathrm{O}_{3}-\mathrm{Fe}_{2} \mathrm{O}_{3}$. J Non Cryst Solids 1998, 231:227-233.

[47] Liu QQ, Yang J, Cheng XN. Study on the preparation of $\mathrm{Fe}_{2} \mathrm{Mo}_{3} \mathrm{O}_{12}$ and its negative thermal expansion property. Adv Mat Res 2011, 287-290: 373-376.

[48] Meyer MK, Thom AJ, Akinc M. Oxide scale formation and isothermal oxidation behavior of Mo-Si-B intermetallics at $600-1000{ }^{\circ} \mathrm{C}$. Intermetallics 1999, 7:153162.

[49] Sun J, Li T, Zhang G-P. Effect of thermodynamically metastable components on mechanical and oxidation properties of the thermal-sprayed $\mathrm{MoSi}_{2}$ based composite coating. Corros Sci 2019, 155:146-154.

[50] Trabelsi H, Bejar M, Dhahri E, et al (2017) Effect of oxygen vacancies on $\mathrm{SrTiO}_{3}$ electrical properties. J Alloys Compd 723:894-903.

[51] Silva MAS, Oliveira RGM, Sombra ASB. Dielectric and microwave properties of common sintering aids for the manufacture of thermally stable ceramics. Ceram Int 2019, 45:20446-20450.

[52] Macdonald JR, Barsoukov E. Impedance spectroscopy: theory, experiment, and applications. John Wiley, 2017.

[53] Paiva DVM, Silva MAS, Sombra ASB, Fechine PBA. Properties of the $\mathrm{Sr}_{3} \mathrm{MoO}_{6}$ electroceramic for RF/microwave devices. J Alloys Compd 2018, 748:766-773.

[54] Wang D, Zhou D, Song K, et al. Cold-sintered C0G multilayer ceramic capacitors. Adv Electron Mater 2019, 5:1900025.

[55] Wang $\mathrm{H}$, Chen $\mathrm{J}$, Yang $\mathrm{W}$, et al. Effects of $\mathrm{Al}_{2} \mathrm{O}_{3}$ addition on the sintering 
behavior and microwave dielectric properties of $\mathrm{CaSiO}_{3}$ ceramics. $J$ Eur Ceram Soc 2012, 32:541-545.

[56] Sebastian MT. Dielectric materials for wireless communication. Elsevier, 2010.

[57] Huang C-L, Yang W-R, Chen Y-R. Improvements in the sintering behavior and microwave dielectric properties of $\mathrm{Mg}_{4} \mathrm{Nb}_{2} \mathrm{O}_{9}$ by adding $\mathrm{Fe}_{2} \mathrm{O}_{3}$. J Alloys Compd 2010, 495:L5-L7.

[58] de Castro AJN, Bessa VL, de Morais JE V, et al. A study of the dielectric and electrical properties of the matrix composite $\left[\mathrm{Ba}_{2} \mathrm{CoNbO}_{6}(\mathrm{BCNO})_{1-\mathrm{X}}-\mathrm{CaTiO}_{3}\right.$ (CTO)X]. Mater Res Bull 2019, 113:169-174.

[59] Oliveira RGM, Silva RA, de Morais JE V, et al. Effects of $\mathrm{CaTiO}_{3}$ addition on the microwave dielectric properties and antenna properties of $\mathrm{BiVO}_{4}$ ceramics. Compos Part B Eng 2019, 175:107122.

[60] Paiva DVM, Silva MAS, de Oliveira RGM, et al. Magneto-dielectric composite based on $\mathrm{Y}_{3} \mathrm{Fe}_{5} \mathrm{O}_{12}-\mathrm{CaTiO}_{3}$ for radio frequency and microwave applications. $J$ Alloys Compd 2019, 783:652-661. 
Figures

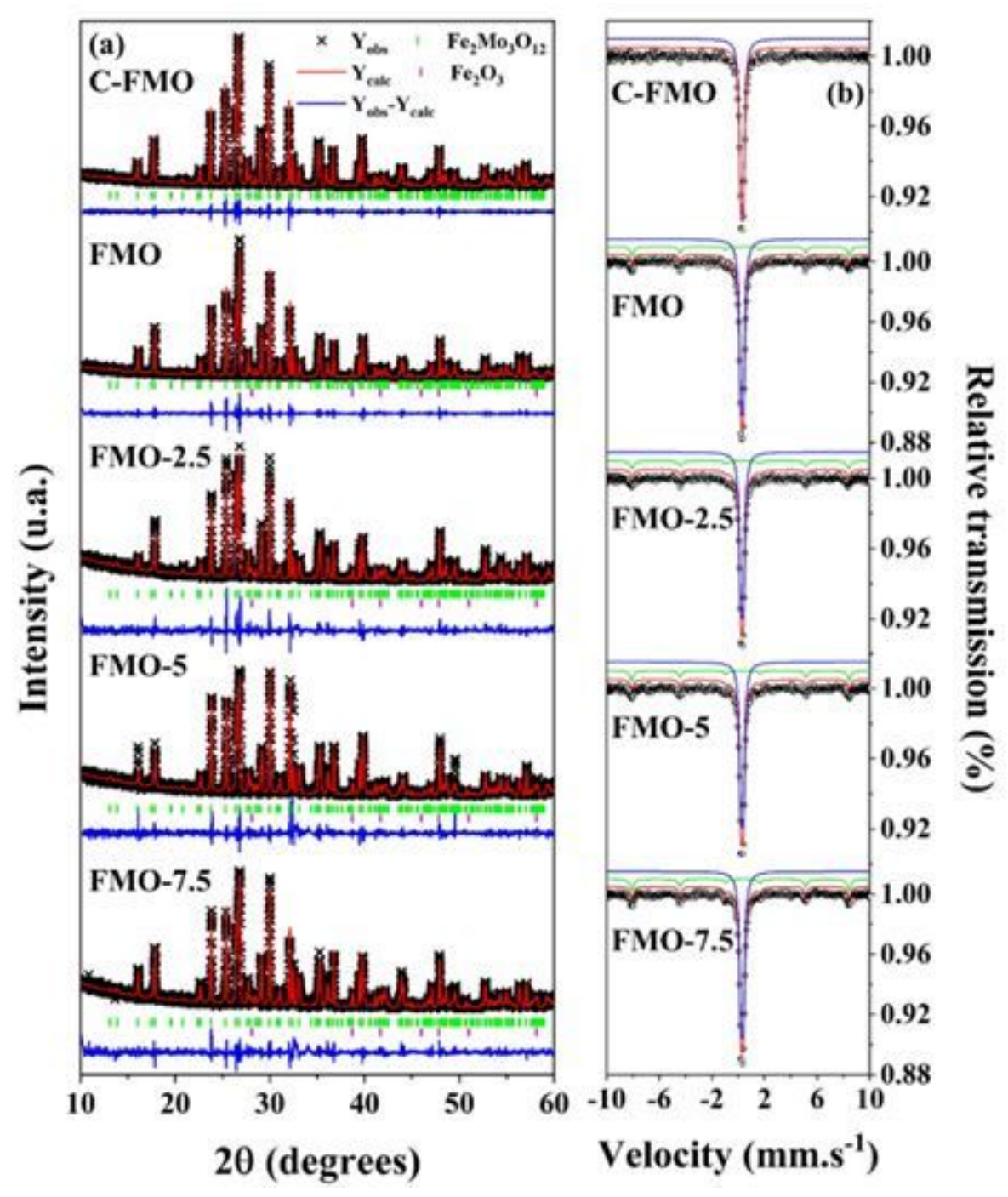

Figure 1

Rietveld refinement of the XRPD (a) with observed (YObs) and calculated (YCalc) intensities and Mössbauer spectra (b) of C-FMO, FMO, FMO-2.5, FMO-5.0 and FMO-7.5. 


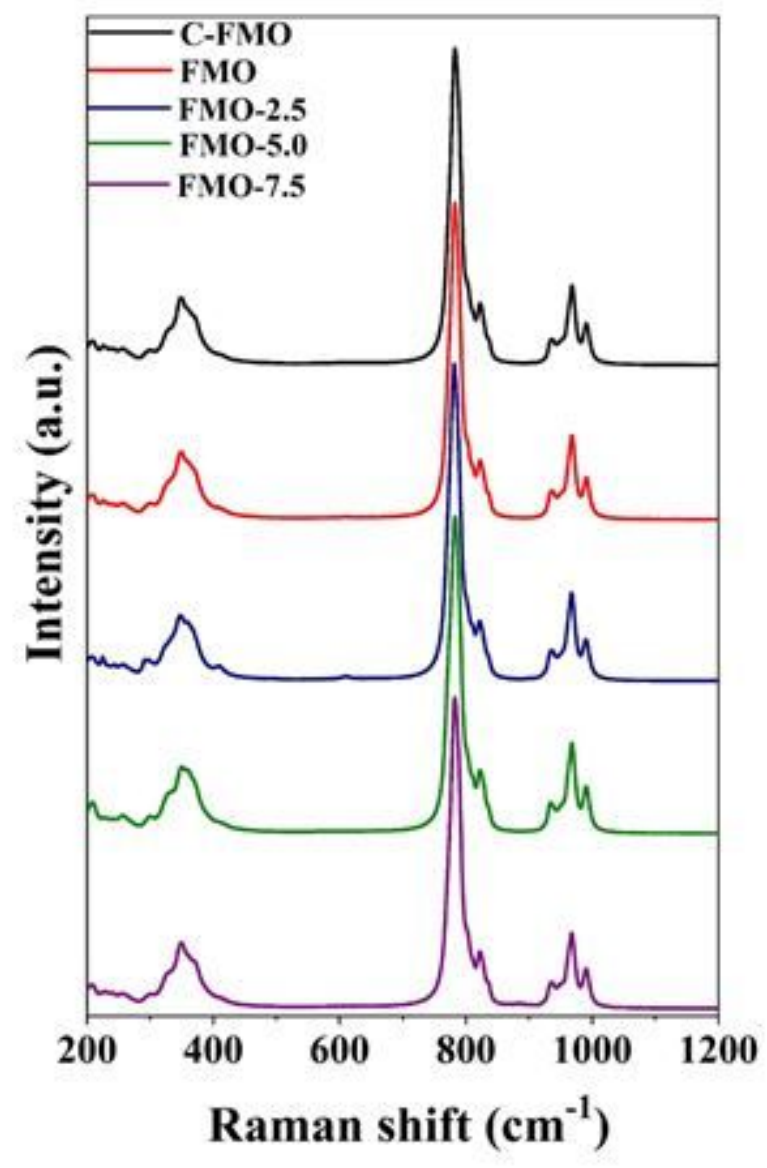

Figure 2

Raman spectra of C-FMO, FMO, FMO-2.5, FMO-5.0 and FMO-7.5. 

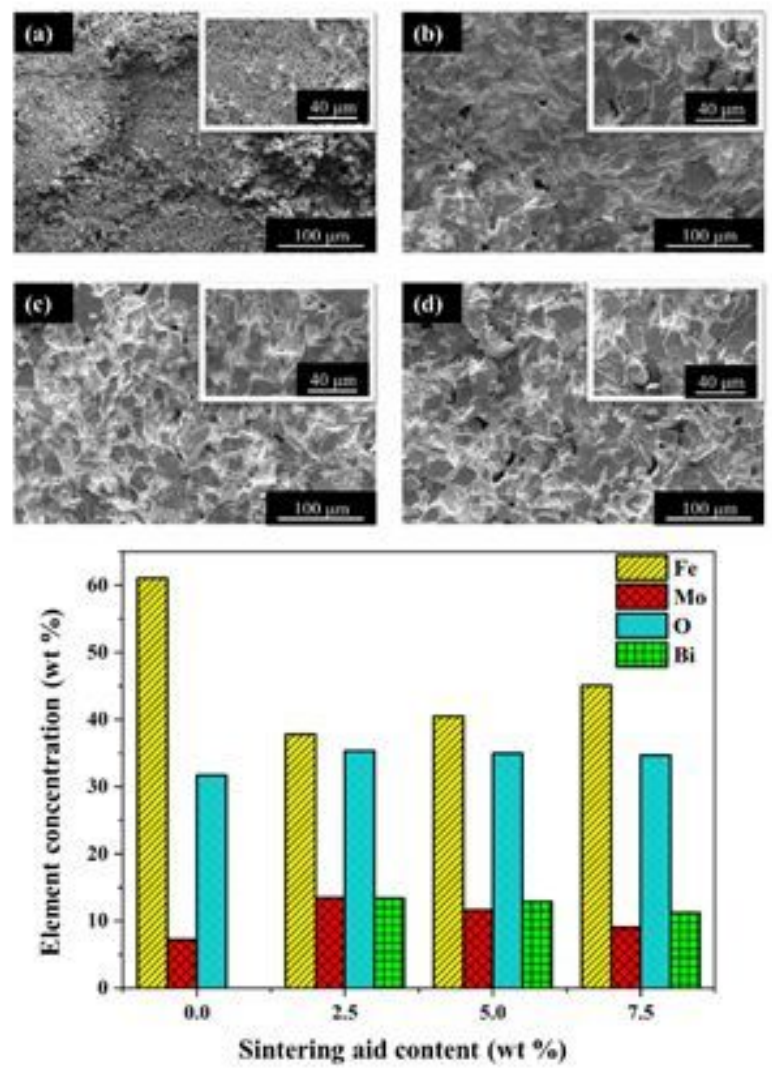

Figure 3

Surface micrograph of (a) FMO, (b) FMO-2.5, (c) FMO-5.0 and (d) FM0-7.5 pellets. Percentage composition in mass ratio versus sintering aid content (e).

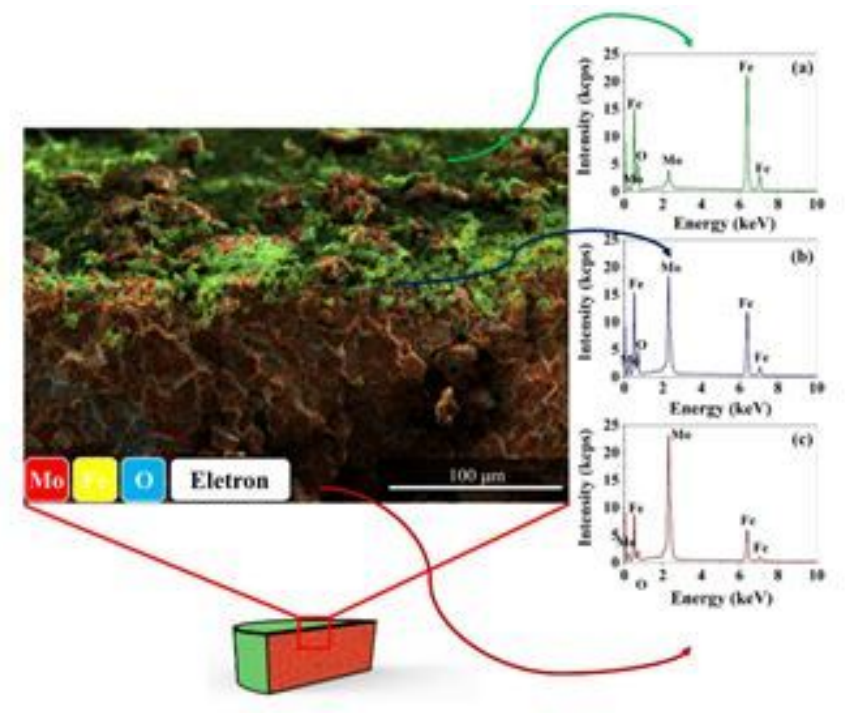

Figure 4

Cylindrical pellet scheme and EDS spectra of different areas. (a) Surface, (b) surface/inner interface and (c) inner. 

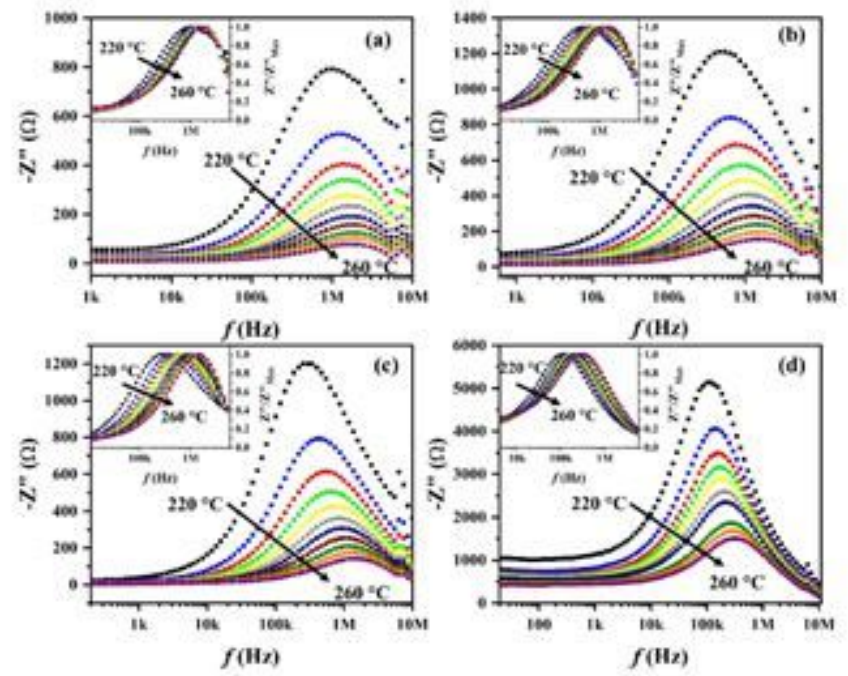

Figure 5

Z" spectra of (a) FMO, (b) FMO-2.5, (c) FMO-5.0 and (d) FMO-7.5. Normalized Z" spectrum (inset).

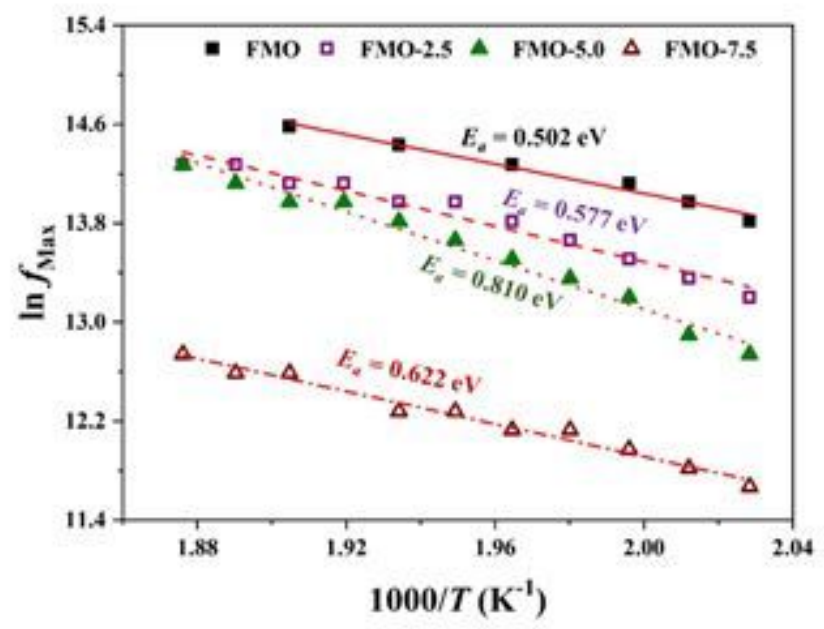

Figure 6

Activation energy of FMO, FMO-2.5, FMO-5.0 and FMO-7.5. 

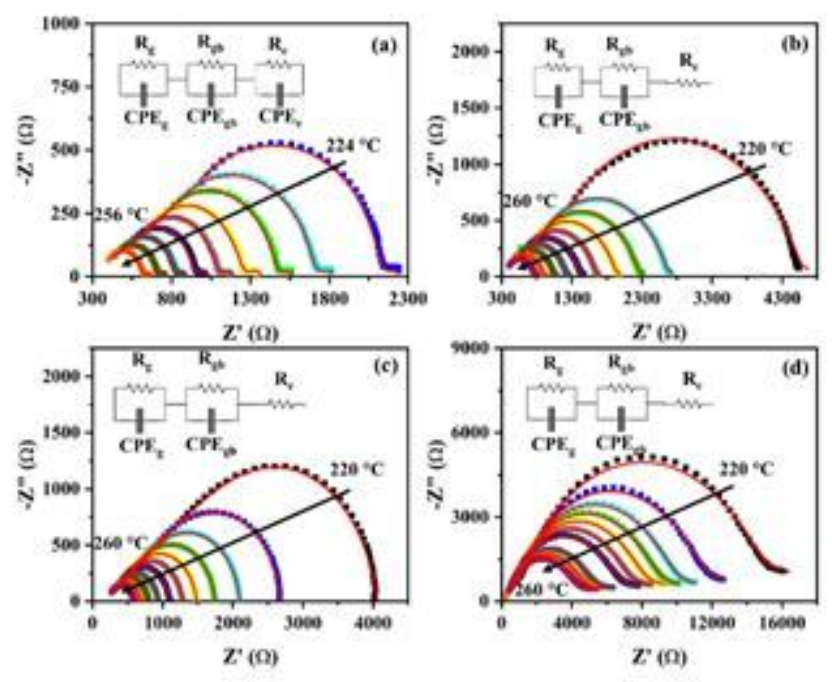

Figure 7

-Z" versus Z' of (a) FMO, (b) FMO-2.5, (c) FMO-5.0 and (d) FMO-7.5

\section{Supplementary Files}

This is a list of supplementary files associated with this preprint. Click to download.

- ElectronicSupplementaryMaterialJACE.docx 